\title{
Deforestation, leakage and avoided deforestation policies: a spatial analysis
}

Article

Accepted Version

Creative Commons: Attribution-Noncommercial-No Derivative Works 4.0

Delacote, P., Robinson, E. J. Z. ORCID: https://orcid.org/00000002-4950-0183 and Roussel, S. (2016) Deforestation, leakage and avoided deforestation policies: a spatial analysis. Resource and Energy Economics, 45. pp. 192-210. ISSN 0928-7655 doi:

https://doi.org/10.1016/j.reseneeco.2016.06.006 Available at https://centaur.reading.ac.uk/66090/

It is advisable to refer to the publisher's version if you intend to cite from the work. See Guidance on citing.

Published version at: http://dx.doi.org/10.1016/j.reseneeco.2016.06.006

To link to this article DOI: http://dx.doi.org/10.1016/j.reseneeco.2016.06.006

Publisher: Elsevier

All outputs in CentAUR are protected by Intellectual Property Rights law, including copyright law. Copyright and IPR is retained by the creators or other copyright holders. Terms and conditions for use of this material are defined in the End User Agreement.

\section{www.reading.ac.uk/centaur}

\section{CentAUR}


Central Archive at the University of Reading

Reading's research outputs online 


\section{Accepted Manuscript}

Title: Deforestation, Leakage and Avoided Deforestation Policies: A Spatial Analysis

Author: Philippe Delacote Elizabeth J.Z. Robinson Sébastien Roussel

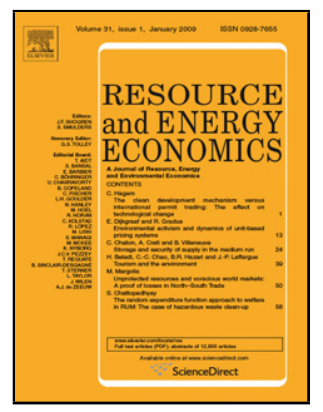

PII: S0928-7655(16)30173-7

DOI: http://dx.doi.org/doi:10.1016/j.reseneeco.2016.06.006

Reference: RESEN 989

To appear in: Resource and Energy Economics

Received date: 21-12-2014

Revised date: 29-3-2016

Accepted date: $30-6-2016$

Please cite this article as: Philippe Delacote, Elizabeth J.Z. Robinson, Sébastien Roussel, Deforestation, Leakage and Avoided Deforestation Policies: A Spatial Analysis, <![CDATA[Resource and Energy Economics]]> (2016), http://dx.doi.org/10.1016/j.reseneeco.2016.06.006

This is a PDF file of an unedited manuscript that has been accepted for publication. As a service to our customers we are providing this early version of the manuscript. The manuscript will undergo copyediting, typesetting, and review of the resulting proof before it is published in its final form. Please note that during the production process errors may be discovered which could affect the content, and all legal disclaimers that apply to the journal pertain. 


\section{Deforestation, Leakage and Avoided Deforestation Policies:}

\section{A Spatial Analysis}

Philippe Delacote ${ }^{12} 2^{3} \quad$ Elizabeth J. Z. Robinson ${ }^{4} \quad$ Sébastien Roussel ${ }^{6} 7$

March 25, 2016

\footnotetext{
${ }^{1}$ Laboratoire d'Economie Forestière, INRA, AgroParisTech, 54000, Nancy, France

${ }^{2}$ Chaire d'Économie du Climat, Paris, France

${ }^{3}$ Contact: philippe.delacote@nancy.inra.fr

${ }^{4}$ University of Reading, School of Agriculture, Policy and Development, United Kingdom

${ }^{5}$ Contact: e.j.robinson@reading.ac.uk

${ }^{6}$ Université Paul Valéry Montpellier 3 (UPVM3), UMR 5474 LAMETA, F-34000 Montpellier, France

${ }^{7}$ Contact: sebastien.roussel@lameta.univ-montp1.fr, sebastien.roussel@univ-montp3.fr
} 


\begin{abstract}
This paper analyses the impact of several avoided deforestation policies within a patchy forested landscape. Central is the idea that one neighbour's deforestation actions may impact the returns to deforestation in nearby patches. We determine the impact of each policy in terms of avoided deforestation and leakage levels at the landscape scale through modelling and simulations. Avoided deforestation policies at a landscape level are respectively: two Payment for Environmental Services (PES) policies, one focused on deforestation hotspots, the second being equally available to all agents; a conservation area; and, an agglomeration bonus. Because our model accommodates spatial interactions in the absence of a deforestation policy, it is possible that a spatial policy can affect both within-intervention areas and outside-intervention spatial spillovers in terms of leakage across different landowners' forest patches. These two different elements of the total extent of displacement across the full landscape have not been considered before. Our contribution is twofold. In terms of methodology, we expand the concept of leakage in accounting for direct impacts to adjacent patches and spatial spillovers over the landscape, and we provide a measure of leakage in a dynamic manner for policy assessment. From our analytical model and simulations, we show that leakage is sensitive to the spatial distribution of forest patch types. The two PES policies are the most cost-effective policies regarding avoided deforestation. The agglomeration bonus policy is efficient at the expense of a higher cost, while the conservation area policy is efficient when patches with similar characteristics are gathered.
\end{abstract}

Keywords: Avoided deforestation, Leakage, Payments for environmental services, Conservation area, Agglomeration bonus, Spatial analysis.

JEL classification: C63, O13, Q23, Q54. 
Highlights of manuscript "Deforestation, Leakage and Avoided Deforestation Policies: A Spatial Analysis"

$\rightarrow$ Agents spatial distribution impact avoided deforestation policies effectiveness.

$\rightarrow$ The leakage and avoided deforestation patterns of four policies are analyzed.

$\rightarrow$ Agglomeration bonuses reduce leakage, decrease the incentive to reduce deforestation. 
Deforestation, Leakage and Avoided Deforestation Policies:

A Spatial Analysis

March 29, 2016 


\begin{abstract}
This paper analyses the impact of several avoided deforestation policies within a patchy forested landscape. Central is the idea that one neighbour's deforestation actions may impact the returns to deforestation in nearby patches. We determine the impact of each policy in terms of avoided deforestation and leakage levels at the landscape scale through modelling and simulations. Avoided deforestation policies at a landscape level are respectively: two Payment for Environmental Services (PES) policies, one focused on deforestation hotspots, the second being equally available to all agents; a conservation area; and, an agglomeration bonus. Because our model accommodates spatial interactions in the absence of a deforestation policy, it is possible that a spatial policy can affect both within-intervention areas and outside-intervention spatial spillovers in terms of leakage across different landowners' forest patches. These two different elements of the total extent of displacement across the full landscape have not been considered before. Our contribution is twofold. In terms of methodology, we expand the concept of leakage in accounting for direct impacts to adjacent patches and spatial spillovers over the landscape, and we provide a measure of leakage in a dynamic manner for policy assessment. From our analytical model and simulations, we show that leakage is sensitive to the spatial distribution of forest patch types. The two PES policies are the most cost-effective policies regarding avoided deforestation. The agglomeration bonus policy is efficient at the expense of a higher cost, while the conservation area policy is efficient when patches with similar characteristics are gathered.
\end{abstract}

Keywords: Avoided deforestation, Leakage, Payments for environmental services, Conservation area, Agglomeration bonus, Spatial analysis.

JEL classification: C63, O13, Q23, Q54. 


\section{Introduction}

High rates of deforestation and forest degradation continue to be of concern in many Low and Middle-Income Countries (LMICs), particularly so in the context of climate change and the role of forests in carbon sequestration. Where forests are owned and managed by private individuals, these private agents choose their optimal rate of deforestation based on the relative private costs and benefits of converting land. However, these forests may provide additional benefits that are not captured by the agent themselves, thus resulting in socially suboptimal levels of forest conversion. In the context of climate change, governments can attempt to influence private agents' decisions over how much of their forestland to convert to agriculture so as to align private and socially optimal choices. Governments might variously rely on regulation, the introduction of conservation areas or economic incentives such as Payments for Ecosystem Services (PES).

Increasingly it is recognised both in the literature and by policy makers that the impact and efficacy of such policies depend not just on the specific details of the intervention, but also on spatial interactions across the forest landscape, and in particular, on the extent of "leakage". In the context of greenhouse-gas emissions and the REDD+ (Reduced Emissions from Deforestation and Forest Degradation) mechanism, leakage is the term given to a "net increase of greenhouse-gas emissions in an area outside the project resulting from the [project] activity" (Schwarze et al., 2002), and occurs "whenever the spatial scale of intervention is inferior to the full scale of the targeted problem" (Wunder, 2008). Leakage is recognized in the Bali Action Plan - COP 13 as a "displacement of emissions" whereby a reduction in greenhouse-gas emissions in one area (or activity) leads to higher emissions in another area (or activity). Such leakage can occur through so-called "activity-shifting leakage" whereby individuals responsible for deforesting and forest degradation shift some or all of their activity from the more protected REDD forest to a less protected location (Aukland et al., 2003, van Oosterzee et al., 2012); or "market or partial / general equilibrium leakage" (Gan and McCarl, 2007; Meyfroidt and Lambin, 2009; Rosendahl and Strand, 2011; Carbone, 2013) in which the leakage is transmitted through markets, reflected in changes in price for forest resources. ${ }^{1}$ Addressing leakage has been widely recognised as a major challenge when designing climate mitigation policies that incorporate a REDD+ scheme (Wunder, 2008; Albers and Robinson, 2013).

\footnotetext{
${ }^{1}$ Leakage has similarly been referred to with respect to conservation policies. For example, evaluation of the U.S. Conservation Reserve Program (CRP) (Wu, 2000; Wu et al., 2001; Roberts and Bucholtz, 2005; Lichtenberg and Smith-Ramirez, 2011), highlighted substitution slippage (activity-shifting-based leakage) and output-price slippage (market-based leakage) as reducing the policy effectiveness.
} 
Thus, whilst a particular initiative might be demonstrated to be successful in terms of reducing deforestation within the project boundaries, if deforestation is displaced outside the project area, then the actual effectiveness of the policy will be lowered.

Only a small number of papers in the literature have developed explicitly spatial models of leakage towards deforestation and public policies. Among them, Murray et al. (2004) explore the impact of leakage from a reserve to a forested area outside a reserve through a "price-induced supply response". The presence of a reserve creates an excess demand for timber relative to the reduced supply, the price rises, and the excess demand is met from outside the reserve. Gan and McCarl (2007) develop a theoretical model of transnational leakage. Again, the mechanism is through prices, and the extent of leakage is determined by the price elasticities of supply and demand for forest products. Robinson et al. (2011) demonstrate theoretically that reduced deforestation due to the implementation of a protected area is likely to increase nearby deforestation when labour and product markets are not functioning efficiently, but have no local impact when markets are efficient. Delacote and Angelsen (2015) propose an understanding of the pattern of shifting activities that may create leakage between agricultural expansion and forest products harvesting: when land and labour are complements in the net return function of the households, a policy aiming at reducing deforestation may indirectly increase forest degradation.

In addition to these contributions, there is a growing body of literature that aims at evaluating policy effectiveness whilst combining modeling and empirical strategy in taking into account net effects of leakage (Wear and Murray, 2004; Murray, 2008; Honey-Roses et al., 2011; Miteva et al., 2011; Alix-Garcia et al., 2012; Baylis et al., 2013; Sims, 2014). In particular, Alix-Garcia et al. (2012) propose an evaluation of Mexico's national payments for hydrological services program Pago por Servicios Ambientales-Hidrológico (PSAH) under both types of slippage. They show that this PES program had relatively moderate impacts on deforestation between 2003 and 2006. They provide evidence for both types of leakage, of which the substitution slippage effect reduced avoided deforestation by about $4 \%$. Sims (2014) studies the impacts of wildlife sanctuaries and national parks in North and Northeast Thailand that are strictly protected areas. She develops and applies an approach for retrospective empirical evaluation of policy impacts on habitat fragmentation, whilst dividing regional landscapes into "micro-landscapes" to assess whether and to what extent protected areas prevented forest loss and fragmentation. She shows that forest cover increased by an estimated 19\%, whereas average forest patch size and maximum forest patch size increased respectively by $25 \%$ and by $21 \%$, compared to a counterfactual scenario of no protection. 
Yet even without explicit policy interventions, there are likely to be spatial interactions due to deforestation choices in one area influencing those in other areas, that is, non-policy-induced leakage. Indeed, Robalino and Pfaff (2012) suggest that "interactions should be considered in predicting deforestation over space and time (...) when designing spatial incentive schemes." They find empirically in Costa Rica that for a given location, neighboring deforestation raises the probability of deforestation, an example of negative leakage, or complementarity in clearing (the opposite finding would be an example of classic leakage, or substitutability in clearing). This observation raises the possibility of strategic substitutability and strategic complementarity, either in clearing or in conservation (Robalino and Pfaff, 2012). ${ }^{2}$ These observations suggest that there is a need to analyse situations of strategic interaction before any governmental interventions, thus recognizing non-policy induced leakage, in addition to policy-induced leakage. ${ }^{3}$

In this paper, we develop a spatial model of deforestation that takes explicit account of spatial interactions (leakage) both before and after a policy intervention designed to reduce the overall rate of deforestation. In doing so we identify both conventional leakage outside of an intervention area due to a spatial policy, and the additional spatial spillovers that occur among areas of land within the intervention area. This leakage that is within the intervention area, due to the interaction of policy and natural spatial interdependencies, occurs because the intervention area encompasses areas of land which, though all are affected by the policy, are owned and managed independently by different agents who take account of this internal leakage. As such, our paper contributes to the growing literature on REDD+, by incorporating localised spatial spillovers - internal leakage - due to the strategic interactions among landowners who are affected by a common REDD+ policy, something that has not been addressed to date in the literature. ${ }^{4}$ In addition to adjacent patches being linked through localised spatial spillovers such that one neighbour's deforestation actions may impact the returns to deforestation to those around them, we accommodate a second explicitly spatial aspect of forest landscapes by allowing forest patches to be heterogeneous in terms of the returns to forestry that they offer.

\footnotetext{
${ }^{2}$ Amin et al. (2014) and Sauquet et al. (2014) present cases of spatial strategic interactions between municipalities in Brazil, which can be considered as leakage in a situation of strategic substitutability.

${ }^{3}$ In connection with these strategic interactions and the impact of policy implementation, one has to observe the sign of leakage. Baylis et al. (2013) (following Armsworth et al. (2006) or Oliveira et al. (2007)) states that "more commonly, leakage is positive resulting from increased pressure to deforest in adjacent lands, relocation of indigenous communities from protected areas to adjacent areas or by preemptive clearing of forest by landowners around newly created restricted-use areas" .

${ }^{4}$ Though we recognize the importance of forest degradation for climate and REDD + , in this paper we restrict our analysis to deforestation.
} 
We explore the implications of four policies aimed at reducing deforestation at a landscape level: two PES policies, that can be likened to REDD+ policies - one focused on deforestation hotspots, the second being equally available to all agents (Bond et al., 2009; Alix-Garcia and Wolff, 2014); a conservation area (Sims, 2014; Amin et al., 2014); and an agglomeration bonus that rewards adjacent patches of lower deforestation in a spatially structured landscape (Parkhurst and Shogren, 2008; Wätzold and Drechsler, 2014). We determine the impact of each policy in terms of avoided deforestation and leakage levels at the landscape scale, relative to the no-policy scenario, through modelling and simulations. Because our model takes account of spatial interactions in the absence of a deforestation policy, it accommodates spatial policy that can affect both within-intervention areas and outside-intervention spatial spillovers in terms of leakage. These two different elements of the total extent of displacement across the full landscape have not been considered before. Our contribution is thus twofold. First, as a conceptual framework, we expand the concept of leakage to account for direct impacts to adjacent patches and spatial spillovers over the landscape, thereby providing a measure of leakage in a dynamic manner for policy assessment. Second, from our analytical model and simulations, we show that leakage is sensitive to the spatial distribution of forest patch types. Our model demonstrates that the optimal policy depends on both costs and the spatial landscape. Specifically, the two PES policies are the most cost-effective policies regarding avoided deforestation. The agglomeration bonus policy is most effective in reducing leakage but at a higher cost, while the conservation area policy is most effective when patches are clustered.

The remainder of this paper is organised as follows. In Section 2, we present our spatial model. In Section 3, we describe the policies that aim to reduce deforestation and consider their implications in terms of avoided deforestation and leakage at the landscape scale. In Section 4, we provide a simulation analysis to illustrate how spatial patterns of deforestation evolve over time, depending on the spatial distribution and the interdependences between patches within this landscape, and we compare those policy options in terms of avoided deforestation, leakage and cost-effectiveness at the landscape scale. We conclude in Section 5.

\section{The model}

The model is set up in the following way. We consider a landscape comprising a finite number of adjacent forest patches of equal size - a priori uniform cells in a grid. Each forest patch is managed individually by one agent. At the beginning of each period, each agent chooses how much of their individual forest patch to deforest, so as to maximise their individual net present returns. To isolate 
spatial interactions, we assume that agents only get value from converting forest land. Thus we consider an agent's net present return to deforesting as follows.

$$
\max _{D_{i t}} \pi_{i t}\left(D_{i t}, X_{i t}, \sum_{j \neq i} \alpha_{i j} D_{j t-1}\right)
$$

The payoff obtained from deforestation is increasing and concave $\left(\frac{\partial \pi_{i t}}{\partial D_{i t}}>0 ; \frac{\partial^{2} \pi_{i t}}{\partial D_{i t}^{2}}<0\right)$.

Agent i's payoff in a specific period is a function of their own chosen deforestation level $D_{i t} ;^{5}$ the exogenous characteristics of that agent's forest patch, $X_{i t}$, such as slope and access to markets; and the agent's neighbours' previous-period deforestation decisions on the adjacent forest patches in the landscape, $D_{j t-1}$, combined with the distance (or intensity of interaction), $\alpha_{i j}$, from those neighbours. The neighbours' previous-period choices combined with the intensity of the interaction together determine the size of a spatial externality. This externality is a recursive relationship between agent $i$ 's current deforestation and its neighbours $j$ 's previous-period deforestation levels. $\alpha_{i j}$ close to 0 indicates relatively small interactions whilst, $\alpha_{i j}$ close to 1 indicates relatively large interactions. Thus the model is constructed such that the optimal per-period level of deforestation for any particular agent only changes over time due to the neighbour interaction term, and so with no interaction, each agent deforests at a constant rate over time.

Equation (1) is a reduced form equation that is consistent with local market-based leakage. For example, it can represent the profit maximization behavior of individuals when the selling price at one location is influenced by the amount being sold by neighbours, such as due to localized markets created by poor infrastructure and resulting high transport costs (Alix-Garcia et al., 2012). Equally, it is consistent with activity-shifting leakage such as due to the migration of agricultural labourers from one patch to another which changes the equilibrium price of labor. In each case, relative prices change due to localized imperfect markets (Robinson et al., 2011) (see Appendix A for more details on the microeconomic foundations of Equation (1)).

The first-order conditions from Equation (1) implicitly gives the optimal level of deforestation $D_{i t}^{*}$ of agent's patch, which in turn depends on that patch's own characteristics and the neighbours' previous optimal deforestation levels $D_{j t-1}^{*}$ :

$$
D_{i t}^{*}=D_{i t}\left(X_{i t}, \sum_{j \neq i} \alpha_{i j} D_{j t-1}^{*}\right)
$$

\footnotetext{
${ }^{5}$ Any deforestation is permanent (such as conversion to agriculture), and so there is no forest regeneration term. However, an agent could choose to actively reforest, in which case the forest cover would increase, and would be indicated by a negative deforestation term.
} 
The level of net deforestation at time $t$ across the landscape is given by:

$$
D_{t}=\sum_{i} D_{i t}^{*}
$$

A spatial externality occurs when a change in one agent's level of deforestation results in a change in the marginal payoff of their neighbours, and thus their neighbours' optimal choice of deforestation. A spillover takes place if a previous decrease (resp. increase) in agent $j$ 's deforestation increases (resp. decreases) agent $i$ 's deforestation: $\frac{\partial D_{i t}^{*}}{\partial D_{j t-1}^{*}}<0$. It is straightforward to show that this is true whenever: $\frac{\partial \pi_{i t}}{\partial D_{i t} \partial\left(\alpha_{i j} D_{j t-1}\right)}<0$. The spatial externality is stronger when $\alpha_{i j}$ is larger. By structuring our model in this way, for any patch, any change in the rate of deforestation from period one is therefore due solely to spatial interactions with neighbouring patches, and thus nonpolicy-induced leakage can be identified clearly. Time $t=0$ defines the initial conditions without spatial interactions. Thus deforestation at time $t=0$ is given by $D_{i 0}^{*}=D_{i t}\left(X_{i t}, 0\right)$, and this is the steady level of deforestation that each agent would experience each period (until no forest in their patch remained) if $\alpha_{i j}=0$, that is, if there were no spatial interactions.

For simplicity and to further explore our model, we consider in the following sections that the type of forest patch is invariant across time, i.e., $X_{i t}=X_{i}$ at any time period $t$. Moreover, we accommodate two types of forest patch. If $X_{i}=\bar{X}$, the direct benefits of deforestation in that patch are high. If $X_{i}=\underline{X}$, the direct benefits of deforestation in that patch are low. We solve our model for two ex ante spatial distribution patterns, one in which patch types are "clustered", and another one in which patch types are "dispersed" . In a clustered case, adjacent forest patches tend to be of the same type. In contrast, in a dispersed case, adjacent forest patches tend to be of different types. The dispersed case could be a proxy for a landscape which has some forest patches where the potential returns to agriculture are high, making deforestation more attractive, and others where the returns are low, perhaps driven by varying elevation, land fertility, access to water, or access to markets. We consider here that only direct neighbours' choices over deforestation influence agent $i$ 's payoff. Thus, $\alpha_{i j} \in[0 ; 1]$ if $i$ and $j$ are direct neighbours, $\alpha_{i j}=0$ if not. ${ }^{6}$ We allow for two levels of interaction: low $\underline{\alpha}$, and high $\bar{\alpha}$. To sum up, these features allow for a spatial distribution over a landscape with a spatial dispersion of heterogeneity in returns. In other words, forest patches are heterogeneous in terms of the returns to forestry that they offer.

\footnotetext{
${ }^{6}$ Nevertheless, the model could also apply for homogeneous spatial effects over the patches space. This may bring different results.
} 


\section{Avoided deforestation policies and leakage}

When a policy is implemented, additional policy-induced spatial spillovers are created. In this section we explicitly expand the concept of leakage to include both within- and outside-intervention spatial spillovers.

***** Figure Expanding the concept of leakage here ${ }^{* * * * * * * * * *}$

First, "treated" agents whose patches lie within a policy intervention area change their optimal deforestation choices in response to the policy. These new deforestation decisions change relative prices for agents on adjacent "non-treated" patches outside the intervention area that are not directly affected by the policy. This is the usual definition of leakage. In addition, treated patches can affect adjacent treated patches; and non-treated patches that are affected by treated patches in turn can have an impact on adjacent non-treated and treated patches. Thus our broader definition of leakage is needed, i.e., the change in deforestation related to spatial interactions and spillovers due to a policy over and above any spatial interactions that occur without the policy. We thus distinguish "TNT leakage" (Treated Non-Treated, i.e., strict definition of leakage between treated and non treated), "TT leakage" (Treated Treated, i.e., within treated policy-induced spatial spillover), and "NTNT leakage" (Non-Treated Non-Treated, i.e., within non treated policy-induced spatial spillover). NTNT leakage can be considered a form of "secondary" leakage, a consequence of "primary" TNT leakage, that can be positive or negative.

As an example, imagine the simple case of three patches, denoted as A, B and C, each managed by a distinct agent. A is B's neighbour, and B is also C's neighbour. A policy is implemented on patch A, and Agent A responds by reducing their deforestation. This deforestation reduction in A increases deforestation in B (primary TNT leakage), an example of localized policy-induced spillovers. The increased deforestation in B (due to a policy enacted in patch A) similarly leads to a decrease in deforestation in C (secondary NTNT leakage).

We assess policy options for reducing deforestation in our spatial setting. With regards to each policy option, the Avoided Deforestation $(A D)$ at time $t$ is measured in the following way:

$$
A D_{t}=D_{t}^{B A U}-D_{t}^{P o l}
$$

Where $D_{t}^{B A U}$ and $D_{t}^{P o l}$ are respectively the deforestation level in the Business-As-Usual (BAU) scenario and the deforestation level with a policy option at the landscape scale (following Equation $(3))^{7}$

\footnotetext{
${ }^{7}$ With $D_{i t}^{B A U}=D_{i t}^{*}, \forall i$.
} 
We explicitly consider the impact of the policy in terms of leakage both on the specific forest patches where the policy is implemented and over the landscape. Spatial interactions are recursive in our model, and they are the only source of dynamics. Therefore there is no policy-induced leakage in the first year of policy implementation. Thus, the difference between avoided deforestation at time greater than $1(t>1)$ and avoided deforestation at time $1(t=1)$ is the result of the spatial interactions that are due to the policy implementation (both within-intervention areas and outsideintervention spatial spillovers). Leakage $(L)$ at time $t$ is measured in the following way:

$$
L_{t}=A D_{t}-A D_{1}
$$

According to Murray et al. (2004) and Murray (2008), leakage is indirectly observable as it is a market phenomenon, and it must be estimated using economic data and models. Its magnitude is expressed as follows (for more details, see the mathematical form in Murray et al. (2004)): L $=$ greenhouse-gas emissions shifted elsewhere / greenhouse-gas emissions directly reduced by the policy. In our spatially finite landscape and to assess and compare the impact of policy implementation over time, we choose a metrics that allowing for variation in leakage from an avoided deforestation target in period $t=1 .^{8}$

We focus on four policy options in our analysis that are respectively:

- A "hotspot" Payment for Environmental Services (PES) policy that focuses on deforestation hotspots (PESh);

- A "full" PES policy applied to all agents (PESf); ${ }^{9}$

- A Conservation Area policy (CA);

- An Agglomeration Bonus policy (AB).

These policies and their assessment are presented in the following subsections.

\subsection{Hotspot payment for environmental services policy}

The hotspot PES policy (PESh) focuses on patches where there is a higher deforestation rate in the absence of policy ( $\bar{X}$-patches). On these patches, the policy maker offers a payment $p_{h}$ to

\footnotetext{
${ }^{8}$ One could design metrics introducing other issues at the patch level like forest fragmentation for example following Sims (2014). However, this is beyond the scope of our paper.

${ }^{9}$ We may underline that in our setting the PES is implemented also in patches where agents reforest effectively. In this case, the PES takes the form of a reforestation incentive.
} 
each agent per unit of avoided deforestation. ${ }^{10}$ Agent $i$ 's payoff thus becomes:

$$
\begin{aligned}
& \max _{D_{i t}} \pi_{i t}\left(D_{i t}, \bar{X}_{i t}, \sum_{j \neq i} \alpha_{i j} D_{j t-1}\right)+p_{h}\left(D_{i t}^{B A U}-D_{i t}\right), \forall i \in[\bar{X}] \\
& \max _{D_{i t}} \pi_{i t}\left(D_{i t}, \underline{X}_{i t}, \sum_{j \neq i} \alpha_{i j} D_{j t-1}\right), \forall i \in[\underline{X}]
\end{aligned}
$$

Where $D_{i t}^{B A U}$ is the deforestation level for agent $i$ in the BAU scenario and $p_{h}$ is the hotspot PES incentive. The first-order conditions of the two kinds of agents bring the equilibrium deforestation level under the hotspot PES policy:

$$
\begin{array}{rlrl}
\frac{\partial \pi_{i t}}{\partial D_{i t}}-p_{h} & =0 & \leftrightarrow D_{i t}^{P E S h} & =D_{i t}\left(X_{i t}, \sum_{j \in[\bar{X}]} \alpha_{i j} D_{j t}^{P E S h}+\sum_{j \in[\underline{X}]} \alpha_{i j} D_{j t}^{P E S h}, p_{h}\right), \forall i \in[\bar{X}] \\
\frac{\partial \pi_{i t}}{\partial D_{i t}}=0 & \leftrightarrow D_{i t}^{P E S h}=D_{i t}\left(X_{i t}, \sum_{j \in[\bar{X}]} \alpha_{i j} D_{j t}^{P E S h}+\sum_{j \in[\underline{X}]} \alpha_{i j} D_{j t}^{P E S h}\right), \forall i \in[\underline{X}]
\end{array}
$$

Comparing Equation (8) to Equation (2) makes clear that agents with $\bar{X}$-patches will decrease their deforestation, $D_{i}^{P E S h}$, when there is a hotspot PES payment, $p_{h}$, compared to the BAU. This deforestation in turn changes the level of between-neighbours spatial spillovers compared to the BAU. Specifically, lower deforestation in the $\bar{X}$-patches due to a PES payment results in greater deforestation in adjacent patches, whatever the patch type, relative to no PES payments. This is the case because: $\frac{\partial D_{i t}^{P E S h}}{\partial \sum_{j \in[\bar{X}]} \alpha_{i j} D_{j t}^{P E S h}}<0, \forall i$.

Thus, by construction, there is always some leakage (TNT or TT) adjacent to each intervention patch when there is a hotspot PES payment, $p_{h}$. Indeed, the decrease in the neighbours' deforestation will have a tendency to increase agent $i$ deforestation. From Equation (9), we see that a type- $\underline{X}$ patch surrounded by $\bar{X}$-patches (dispersed case) tends to increase deforestation compared to the BAU.

The avoided deforestation and leakage at the landscape scale following the PESh policy implementation are then:

$$
\begin{gathered}
A D_{t}^{P E S h}=\sum_{i \in \bar{X}}\left(D_{i t}^{*}-D_{i t}^{P E S h}\right)+\sum_{i \in \underline{X}}\left(D_{i t}^{*}-D_{i t}^{P E S h}\right) \\
L_{t}^{P E S h}=\underbrace{\sum_{i \in \bar{X}}\left(D_{i t}^{*}-D_{i t}^{P E S h}\right)-\left(\sum_{i \in \bar{X}}\left(D_{i 1}^{*}-D_{i 1}^{P E S h}\right)\right.}_{T T \text { Leakage }}+\underbrace{\left.\sum_{i \in X}\left(D_{i t}^{*}-D_{i t}^{P E S h}\right)+\sum_{i \in \underline{X}}\left(D_{i 1}^{*}-D_{i 1}^{P E S h}\right)\right)}_{T N T+N T N T \text { Leakage }}
\end{gathered}
$$

Thus, when a PES hotspot policy is implemented, any change in deforestation for agents with low deforestation levels relative to BAU is only due to leakage (as they are not targeted by the

\footnotetext{
${ }^{10} p_{h}>0$.
} 
policy). In contrast, the change in deforestation for agents with high deforestation levels (hotspots) is influenced by the PES and by the leakage between the various hotspots. ${ }^{11}$

This leads to the following proposition:

Proposition 1: Under a PES implemented in deforestation hotspots, leakage is stronger when agents are surrounded by neighbours with higher deforestation rates, but secondary NTNT leakage may also take place between non treated. It follows that TT leakage is stronger in a clustered case, while TNT leakage is stronger in a dispersed case. Finally, leakage is more important in a high-interaction case.

Proof: Under a hotspot PES policy, only $\bar{X}$-type agents are targeted. Thus, they are the only agents experiencing a direct decrease of their BAU deforestation $\left(\frac{\partial D_{i t}^{P E S h}}{\partial p_{h}}<0, \forall i \in[\bar{X}]\right)$. It follows that leakage only comes from those agents in the first place. Then, given our spatial setting, leakage impacts more $\bar{X}$-type agents (TT leakage; $\sum_{i \in \bar{X}}\left(D_{i t}^{*}-D_{i t}^{P E S h}\right)-\sum_{i \in \bar{X}}\left(D_{i 1}^{*}-D_{i 1}^{P E S h}\right)$ in a clustered case, and $\underline{X}$-type agents (TNT leakage; $\left.\sum_{i \in \underline{X}}\left(D_{i t}^{*}-D_{i t}^{P E S h}\right)+\sum_{i \in \underline{X}}\left(D_{i 1}^{*}-D_{i 1}^{P E S h}\right)\right)$ in a dispersed case.

\subsection{Full payment for environmental services policy}

Under this full PES policy (PESf), we consider a PES payment $p_{f}$ that is offered to every agent $($ both $\bar{X}$ and $\underline{X}):^{12}$

$$
\max _{D_{i t}} \pi_{i t}\left(D_{i t}, X_{i t}, \sum_{j \neq i} \alpha_{i j} D_{j t-1}\right)+p_{f}\left(D_{i t}^{B A U}-D_{i t}\right), \forall i \in[\underline{X}, \bar{X}]
$$

Where $D_{i t}^{B A U}$ is the deforestation level for agent $i$ in the BAU scenario and $p f$ is the individual full PES incentive. We suppose here that $p_{f}$ is lower than $p_{h}\left(p_{f}<p_{h}\right)$, as the full PES payment is spread over the whole set of agents rather than a sub-set.

The first-order conditions of the two kinds of agents define the equilibrium deforestation level under the full PES policy:

$$
\frac{\partial \pi_{i t}}{\partial D_{i t}}-p_{f}=0 \quad \leftrightarrow D_{i t}^{P E S f}=D_{i t}\left(X_{i t}, \sum_{j \neq i} D_{j t}^{P E S f}, p_{f}\right)
$$

When the full PES payment $p_{f}$ is implemented, it is straightforward to see that all agents directly reduce their deforestation levels. Furthermore, as all agents are concerned by the policy, only one

\footnotetext{
${ }^{11}$ The overall effect brings positive avoided deforestation only for small enough levels of spatial interactions. Conceptually one could imagine spatial interactions large enough to overcome the impact of the policy.

${ }^{12} p_{f}>0$.
} 
type of leakage is left: TT leakage. Therefore, agents surrounded by $\underline{X}$-agents will experience larger leakage compared to the hotspot PES case. This is the case because: $\sum_{j \in[\bar{X}]} \alpha_{i j} D_{j t}^{P E S h}<$ $\sum_{j \in[\bar{X}]} \alpha_{i j} D_{j t}^{P E S f}$ and $\sum_{j \in[\underline{X}]} \alpha_{i j} D_{j t}^{P E S h}>\sum_{j \in[\underline{X}]} \alpha_{i j} D_{j t}^{P E S f}$.

The avoided deforestation and leakage at the landscape scale following the PESf policy implementation are then:

$$
\begin{gathered}
A D_{t}^{P E S f}=\sum_{i}\left(D_{i t}^{*}-D_{i t}^{P E S f}\right) \\
L_{t}^{P E S f}=\underbrace{\sum_{i}\left(D_{i t}^{*}-D_{i t}^{P E S f}\right)-\sum_{i}\left(D_{i 1}^{*}-D_{i 1}^{P E S f}\right)}_{\text {TTleakage }}
\end{gathered}
$$

We can see here that, compared to the PESh policy, leakage now comes from both types of agents.

This leads to the following proposition:

Proposition 2: Under a full PES policy, all agents reduce their deforestation. However, agents surrounded by $\underline{X}$-agents reduce their deforestation less than in a hotspot PES case. It follows that leakage is stronger for $\underline{X}$-agents (resp. weaker for $\bar{X}$-agents) in the full PES case than in the hotspot PES case. The net effect depends on spatial distribution: leakage is stronger (resp. weaker) in the full PES case than in the hotspot PES case when agents are dispersed (resp. clustered).

Proof: Under a full PES, all agents including $\underline{X}$-agents reduce directly their deforestation $\left(\frac{\partial D_{i t}^{P E S f}}{\partial p_{f}}<0, \forall i\right)$. Becoming treated by the policy, they are therefore source of primary leakage for their neighbours. In contrast, $\bar{X}$-type agents are source of smaller leakage for their neighbours compared to the hotspot PES case, as they receive a lower payment $\left(p_{f}<p_{h}\right.$ by assumption; $\left.\left|\frac{\partial D_{i}^{P E S h}}{\partial p_{h}}\right|>\left|\frac{\partial D_{i}^{P E S f}}{\partial p_{f}}\right|, \forall i \in[\bar{X}]\right)$. We directly obtain that there is more leakage (resp. less) in the full PES case than in the hotspot PES case when agents are dispersed (resp. clustered).

The comparison between our two PES implementation is interesting to underline the consequences in terms of leakage. While a strict definition of leakage would let think that implementing a full PES policy is enough to get rid of leakage, our definition shows that this is more complex: "classic" TNT leakage may disappear by construction under a full PES at the expense of TT leakage. 


\subsection{Conservation area policy}

We now turn to the Conservation Area (CA) policy in which considering that the policy maker rents the land from one particular agent $\tilde{i}$, and freezes the land so that no deforestation occurs. ${ }^{13}$

Deforestation in this case takes the form:

$$
\begin{aligned}
D_{\tilde{i} t}^{C A} & =0, \forall i=\tilde{i} \\
D_{i t}^{C A} & =D_{i t}\left(X_{i}, \sum_{j \neq i} \alpha_{i j} D_{j t}^{C A}\right), \forall i \neq \tilde{i}
\end{aligned}
$$

The avoided deforestation and leakage at the landscape scale following the CA policy implementation are then:

$$
\begin{gathered}
A D_{t}^{C A}=D_{\tilde{i} t}^{*}+\sum_{i \neq \tilde{i}} \alpha_{i j}\left(D_{i t}^{*}-D_{i t}^{C A}\right) \\
L_{t}^{C A}=\underbrace{\sum_{i \neq \tilde{i}} \alpha_{i j}\left(D_{i t}^{*}-D_{i t}^{C A}\right)-\sum_{i \neq \tilde{i}} \alpha_{i j}\left(D_{i 1}^{*}-D_{i 1}^{C A}\right)}_{T N T+N T N T \text { leakage }}
\end{gathered}
$$

In this case, when policy efforts are concentrated in one area, leakage is also more geographically focused. Moreover, because by construction there is no TT leakage, we have the following proposition:

Proposition 3: With a CA policy, the protected patch is the sole source of leakage. It follows that leakage is concentrated around the conservation area. Leakage will therefore be more geographically concentrated than under hotspot and full PES schemes. Secondary NTNT negative leakage may however spread as a second belt around direct neighbours of treated areas.

Proof: Under a CA policy, deforestation in the treated zone is imposed to 0. It follows that primary TNT leakage will be by definition concentrated around that particular area. The increase in deforestation in this surrounding zone may in turn create secondary spatial spillovers (NTNT leakage) that can decrease deforestation in the second belt around the treatment area (through $\left.\sum_{i \neq i} \alpha_{i j}\left(D_{i t}^{*}-D_{i t}^{C A}\right)-\sum_{i \neq i} \alpha_{i j}\left(D_{i 1}^{*}-D_{i 1}^{C A}\right)\right)$.

\footnotetext{
${ }^{13}$ We assume here that the cost of implementing protected areas corresponds to paying the opportunity cost of this land. Yet, the actual cost of such policy may differ. Indeed, exclusion and enforcement costs would have to be considered. In addition, the policy maker may choose not to compensate the agent deprived for his land use. Overall, the actual cost can differ a lot from our hypothesis. Yet, we keep this assumption, as it allows a clear and easy comparison between the various policies.
} 


\subsection{Agglomeration bonus policy}

The introduction of an Agglomeration Bonus (AB) policy may be of interest in dealing with adjacent patches whilst providing a joint incentive between agents. The AB policy takes the form of a two-part PES payment: a payment for individual avoided deforestation, $a ;^{14}$ and, a payment that is an agglomeration bonus, which is proportional to previous deforestation in the neighbourhood, $b .{ }^{15}$ For simplicity, we focus here on the hotspot patches ( $\bar{X}$-patches). Consequently, the payment for individual avoided deforestation, $a$, and the agglomeration bonus, $b$, can thus counterbalance leakage that was described in the hotspot PES policy (PESh) case.

The AB policy is then set from:

$$
\begin{aligned}
& \max _{D_{i t}} \pi_{i t}\left(D_{i t}, \bar{X}_{i t}, \sum_{j \neq i} \alpha_{i j} D_{j t-1}\right)+a\left(D_{B A U i t}-D_{i t}\right)+b\left(\sum_{j \neq i} \alpha_{i j} D_{j t-1}\right) D_{i t}, \forall i \in[\bar{X}] \\
& \max _{D_{i t}} \pi_{i t}\left(D_{i t}, \underline{X}_{i t}, \sum_{j \neq i} \alpha_{i j} D_{j t-1}\right), \forall i \in[\underline{X}]
\end{aligned}
$$

The first-order conditions of the two kinds of agents bring the equilibrium deforestation level under the $\mathrm{AB}$ :

$$
\begin{gathered}
\frac{\partial \pi_{i t}}{\partial D_{i t}}-a+b\left(\sum_{j \neq i} \alpha_{i j} D_{j t-1}\right)=0 \\
\leftrightarrow D_{i t}^{A B}=D_{i t}\left(X_{i t}, \sum_{j \in[\bar{X}]} \alpha_{i j} D_{j t}^{A B}+\sum_{j \in[\underline{X}]} \alpha_{i j} D_{j t}^{A B}, a, b\left(\sum_{j \neq i} \alpha_{i j} D_{j t-1}^{A B}\right)\right), \forall i \in[\bar{X}] \\
\frac{\partial \pi_{i t}}{\partial D_{i t}}=0 \quad \leftrightarrow D_{i t}^{A B}=D_{i t}\left(X_{i t}, \sum_{j \in[\bar{X}]} \alpha_{i j} D_{j t}^{A B}+\sum_{j \in[\underline{X}]} \alpha_{i j} D_{j t}^{A B}\right), \forall i \in[\underline{X}]
\end{gathered}
$$

One can see that increasing the agglomeration bonus $b$ has two impacts on deforestation. First, it decreases the impact of the treated neighbours' deforestation, and thus it counterbalances the spatial spillovers. One can thus expect that $b$ will decrease TNT and TT leakage. Second, however, one can show that increasing $b$ also increases the marginal benefit from $i$ 's own deforestation.

The avoided deforestation and leakage at the landscape scale following the AB policy implementation are then:

$$
A D_{t}^{A B}=\sum_{i \in \bar{X}}\left(D_{i t}^{*}-D_{i t}^{A B}\right)+\sum_{i \in \underline{X}}\left(D_{i t}^{*}-D_{i t}^{A B}\right)
$$

\footnotetext{
${ }^{14} a>0$.

${ }^{15} b>0$.
} 


$$
L_{t}^{A B}=\underbrace{\sum_{i \in \bar{X}}\left(D_{i t}^{*}-D_{i t}^{A B}\right)-\left(\sum_{i \in \bar{X}}\left(D_{i 1}^{*}-D_{i 1}^{A B}\right)\right.}_{T T \text { leakage }}+\underbrace{\left.\sum_{i \in \underline{X}}\left(D_{i t}^{*}-D_{i t}^{A B}\right)-\sum_{i \in \underline{X}}\left(D_{i 1}^{*}-D_{i 1}^{A B}\right)\right)}_{T N T+N T N T \text { leakage }}
$$

One can see here that increasing the agglomeration bonus, $b$, indeed reduces leakage by reducing the negative spatial interactions between neighbours. However, it also reduces the avoided deforestation at the landscape scale.

This leads to the following proposition:

Proposition 4: Leakage is decreasing in the AB policy. Leakage may even become negative for sufficiently high levels of agglomeration bonus. However, the agglomeration bonus also decreases avoided deforestation.

Proof: The agglomeration bonus, $b$, decreases the impact of the spatial interaction from the neighbours. Leakage is thus decreasing in $b$. However, deforestation under the PES with a bonus is increasing in the level of $b: \frac{\partial D_{i t}^{A B}}{\partial b}=\sum_{j \neq i} \alpha_{i j} D_{j t-1}^{A B}>0$.

Overall, the level of the agglomeration bonus, $b$, is negatively correlated to agent $i$ neighbours' deforestation: the bonus thus performs as expected and reduces leakage. However, if the agglomeration bonus is effective, it must also increase agent $i$ ? s own deforestation. Increasing the direct payment, $a$, which is done at the expense of a higher total cost, counters this effect. It follows that reducing leakage through an agglomeration bonus is made at the expense of reducing avoided deforestation within the intervention area. The trade-off has to be considered carefully when implementing such type of scheme.

\section{Specification and simulations}

\subsection{Benchmark}

Ours results hold for a general setting. Yet, in order to provide a concrete illustration, we specify functional forms and calibrate the model. We make a number of simplifying assumptions that allow us to ensure clarity of the model whilst not losing any of the key elements that need to be captured. ${ }^{16}$

\footnotetext{
${ }^{16}$ Other types of setting could be specified that would fit with the results of the general model and could bring possible extensions of this paper.
} 
As above, we consider two contrasting patterns of ex ante spatial distribution: clustered and dispersed. These patterns are set for a 5 x 5 grid of 25 adjacent forest patches. Each cell corresponds to one forest patch which is controlled by one agent. These two extreme spatial distributions allow us to emphasize the role of spatial distribution in determining the pattern and extent of leakage.

We consider a simple recursive quadratic payoff function that satisfies the conditions described in Section 2:

$$
\pi_{i t}\left(D_{i t}, X_{i t}, \sum_{j \neq i} \alpha_{i j} D_{j t-1}\right)=\left(\beta X_{i t}-\sum_{j \neq i} \alpha_{i j} D_{j t-1}\right) D_{i t}-\frac{1}{2} D_{i t}^{2}
$$

Thus revenues from deforestation, $D_{i t}$, in the absence of any spatial interaction effects are simply equal to the forest patch type, $X_{i t}$, multiplied by some parameter $\beta,{ }^{17}$ then multiplied by the level of deforestation $D_{i t}$. The costs of deforestation are quadratic, increasing in $D_{i t}$. This non-linearity drives the result that agents typically do not deforest their full forest patch in the first period, and so we have an interior solution. The presence of the interaction term, $\alpha_{i j}$, potentially changes the returns to deforestation.

Assuming an interior solution, the first-order condition of Equation (26) gives the optimal level of deforestation $D_{i}^{*}$ for agent $i$ :

$$
D_{i t}^{*}=\beta X_{i t}-\sum_{j \neq i} \alpha_{i j} D_{j t-1}^{*}
$$

With regards to the avoided deforestation policies described in Section 3, results from this specified model in terms of deforestation, avoided deforestation and leakage are given in Appendix B.

For simulation purpose, we run the model for 10 periods to design BAU scenarios (Figure 2). We distinguish four potential cases depending on whether similar patches are clustered (C) or dispersed $(\mathrm{D})$, and whether there is high $(\mathrm{H})$ or low $(\mathrm{L})$ interaction: Clustered/Low-interaction $(\mathrm{C} / \mathrm{L})$, Clustered/High-interaction (C/H), Dispersed/Low-interaction (D/L), Dispersed/High-interaction $(\mathrm{D} / \mathrm{H})$. The results are given in terms of rates of deforestation for each patch each period. ${ }^{18} \mathrm{~Pa}-$ rameters for the simulation analysis are given in Appendix C.1. ${ }^{19}$

${ }^{18}$ Note that if our modeling was adapted to address forest degradation, these deforestation rates could be reinterpreted as indicators of degradation intensity.

${ }^{19}$ Parameters were chosen here so that the agents in $\bar{X}$-patches have positive rates of deforestation in the BAU, while those in $\underline{X}$-patches have negative rates (meaning they choose to reforest). This choice is made for presentation purpose, as it is easier to distinguish each type on our landscape deforestation maps. It has no implication on the nature of our results, which would be the same if both types of agents deforest in the BAU.
} 
****** Figure Business-as-usual deforestation dynamics here ${ }^{* * * * * * * * *}$

Figure 2 can be understood in the following way. Ex ante, all forest patches of type $\bar{X}$ are identical, and all of type $\underline{X}$ are identical. In the first period, because there is no prior deforestation, all agents $\bar{X}$-patches make the same deforestation choice, as do all agents in $\underline{X}$-patches. There are two types of edge effects. One is imposed by the topology of the simulation model which has a finite number of forest patches such that some patches are at the model landscape boundary and others are not. As such there are edge effects imposed by the spatially finite model structure. ${ }^{20}$ However, of particular interest in this paper are the edge effects that come from forest patches being adjacent to other forest patches where there are agents making active deforestation decisions.

From Figure 2, we can observe a number of dynamic transitions to different steady states constant rates of deforestation depending on the assumptions over the spatial distribution. In the $\mathrm{C} / \mathrm{L}$ case, a steady state is reached after 5 periods. Agents on $\bar{X}$-patches all deforest at the same rate, whether they are adjacent to an edge, to another $\bar{X}$-patch, or a $\underline{X}$-patch. The choices of agents on $\underline{X}$-patches differ however depending on whether they are adjacent to at least one $\bar{X}$ patch, in which case they reforest; or only $\underline{X}$-patch or an edge in which case they deforest. We find cases of reforestation because of the negative spatial interactions from adjacent $\bar{X}$-patches. This reforestation creates a spatial interaction into $\underline{X}$-patches at the bottom of the grid which are adjacent either to other $\underline{X}$-patches or to the boundary. In the $\mathrm{C} / \mathrm{H}$ case, a steady state is reached after 10 periods and is similar to the $\mathrm{C} / \mathrm{L}$ case, though the equilibrium reflects a more complex pattern of interactions. In the $\mathrm{D} / \mathrm{L}$ case, a steady state is reached after 5 periods with patches of reforestation alternating with patches of deforestation. Finally, in the $\mathrm{D} / \mathrm{H}$ case, a steady state is also reached after 5 periods; the pattern remains similar but with higher rates of deforestation and higher rates of reforestation.

Differences in net deforestation $D_{t}$ are driven almost entirely by the forest patch type, rather than the spatial distribution of forest patches. This result is due to our model assumption of

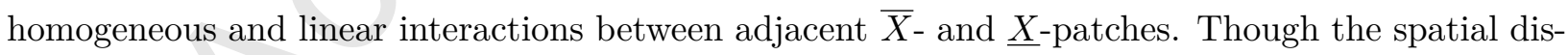
tribution of deforestation is different in the two spatial cases, the overall rate of deforestation is similar. Larger interactions tend to decrease deforestation for both types of agent whilst smaller interactions reduce the variability of deforestation in time. More generally, larger spatial interactions increase deforestation variability.

\footnotetext{
${ }^{20}$ We can imagine some national land outside the grid where $\alpha_{i j}=0$, where there is no scope for deforestation or reforestation, perhaps an urban landscape, or perhaps a fully protected area of forest.
} 


\subsection{Illustration of Propositions 1-4}

Policies are implemented at $t=1$ and the model runs for 10 periods. The policy calibration for each of the policy option is provided in Appendix C.2. All policies are calibrated in order to generate the same avoided deforestation at period $t=1 .^{21}$ The only dynamic parameter in our setting is the spatial externality driven by any policy implementation. Therefore, the following comparison cannot be considered as an assessment of policy options per se, but only of their implications in terms of leakage.

\section{- PESh policy}

An illustration of Proposition 1 is given in Figure 3 with low-interaction. Leakage is stronger (resp. weaker) for $\bar{X}$-agents than for $\underline{X}$-agents in a clustered (resp. dispersed) case. We can indeed see that leakage from $\bar{X}$-agents is more than 4 times the one of $\underline{X}$-agents in the clustered case. In the dispersed case, leakage from $\underline{X}$-agents is about 1.5 times stronger than from $\bar{X}$-agents.

***** Figure Leakage comparison between the $\bar{X}$-agents and $\underline{X}$-agents for the clustered case (left) and the dispersed case (right) (low interactions) here ${ }^{* * * * * * * * *}$

\section{- PESf policy}

In this case, the direct effect of the PES is higher as all agents are offered the payment compared to only hotspot $\bar{X}$-agents. Figures 4 and 5 illustrate Proposition 2, for a lowinteraction case. ${ }^{22}$ Leakage is weaker for $\bar{X}$-agents (resp. stronger for $\underline{X}$-agents) in the full PES case than in the hotspot PES case. Leakage is weaker (resp. stronger) under a full PES than under a hotspot PES in a clustered (resp. dispersed) case.

***** Figure Leakage comparison between the full PES and the hotspot PES policies for $\bar{X}$-agents (left) and $\underline{X}$-agents (right) (low interactions/ clustered case) here********* ***** Figure Leakage comparison between the full PES and the hotspot PES policies for the clustered case (left) and the dispersed case (right) (low interactions)here $* * * * * * * * *$

\section{- CA policy}

\footnotetext{
${ }^{21}$ Thus $p_{h}, p_{f}$ and $a$ are set at different levels.

${ }^{22}$ However note that the difference in terms of leakage is very small in our simulations. This is due to the fact that we assume homogeneous and linear interactions between $\bar{X}$ - and $\underline{X}$-agents. The result would be different if we assumed for instance stronger leakage between high-deforestation agents.
} 
As seen in Figures 6 and $7,{ }^{23}$ leakage is concentrated around the CA in both the C/L case and the D/L case. Second order effect can occur: the CA increases deforestation in the "first belt" around (TNT leakage) which in turn has a spatial feedback on the "second belt" (NTNT leakage) leading to decrease its deforestation.

***** Figure Leakage under the CA policy in the clustered case (low interactions) here ${ }^{* * * * * * * * * *}$

***** Figure Leakage under the $\mathrm{CA}$ policy in the dispersed case (low interac-

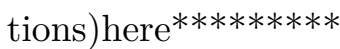

\section{- AB policy}

From Figure 8, we can observe that when $b$ is increased (while $a$ is fixed), leakage is reduced, but overall avoided deforestation is lower. Thus, the direct payment $a$ must be increased to counter this, which increases the total cost of the policy.

***** Figure Leakage and avoided deforestation under the AB policy $\left(b_{1}<b_{2}<b_{3}<b_{4}\right)$ (low interactions/ dispersed case) here ${ }^{* * * * * * * * *}$

\subsection{Policy comparison}

In this subsection, we focus on comparing the four policies presented in Section 3, at the landscape scale and for four spatial distributions $(\mathrm{C} / \mathrm{L}, \mathrm{C} / \mathrm{H}, \mathrm{D} / \mathrm{L}, \mathrm{D} / \mathrm{H})$. Our comparison first considers the levels of avoided deforestation and leakage. Then, we will focus on the costs of the policy, and finally, we will consider cost effectiveness.

\subsubsection{Avoided deforestation and leakage at the landscape scale}

For policy comparison, the respective Avoided Deforestation $(A D)$ and Leakage $(L)$ at the landscape scale are displayed in Figure 9 and Figure 10.

Note first that the ranking of policy impacts depends on the spatial distribution that we consider (Figure 9). ${ }^{24}$ When considering clustered cases, the AB policy is the most effective tool in terms of avoided deforestation. Hotspot and full PES policies bring intermediate results, while the CA policy is the less effective policy instrument. In contrast, in the dispersed cases, the CA policy

\footnotetext{
${ }^{23}$ Note that we use mapping here in the same manner as in Figure 2 to represent the impact of CA in terms of leakage. This is more straightforward to figure out leakage in the CA case, and leakage is expressed in deforestation intensity.

${ }^{24}$ It is important to note here that the results from the AB policy are using the same bonus calibration.
} 
becomes the most effective tool followed by the AB policy. Hotspot and full PES policies are the least effective policy options. Finally, stronger interactions increase the variability of avoided deforestation in time, especially for the CA policy case.

Looking at the impact of the different policies on leakage corroborates our findings. We find the greatest level of leakage for the CA policy in a clustered case, and the least for the AB policy. In contrast, in dispersed cases, the CA policy is associated with the lowest level of leakage. Hotspot and full PES schemes result in the most leakage.

The CA policy has a very different impact, depending on the spatial distribution forest patches. In a clustered case, the conservation area neighbours are also deforestation hotspots, and therefore very sensitive to leakage. In a dispersed case, the conservation area neighbours are low-deforestation type agents, and thus can be considered to act as buffer zones with respect to leakage. Both types of PES schemes have similar results in terms of avoided deforestation and leakage due to the linear form of our specified deforestation function.

$* * * * *$ Figure Avoided deforestation at the landscape scale here ${ }^{* * * * * * * * * *}$

***** Figure Leakage at the landscape scale here $* * * * * * * * *$

\subsubsection{Policy costs}

The costs of the policies are set as follows:

- Hotspot PES policy (PESh): $C_{t}^{P E S h}=\sum_{i \in \bar{X}} p_{h}\left(D_{i t}^{*}-D_{i t}^{P E S h}\right)$

- Full PES policy (PESf): $C_{t}^{P E S f}=\sum_{i \in(\underline{X}, \bar{X})} p_{f}\left(D_{i t}^{*}-D_{i t}^{P E S f}\right)$

- Conservation Area policy (CA): $C_{t}^{C A}=\pi_{\tilde{i} t}$

- Agglomeration Bonus policy $(\mathrm{AB}): C_{t}^{A B}=\sum_{i \in \bar{X}}\left(a\left(D_{i t}^{*}-D_{i t}^{A B}\right)+b\left(\sum_{j \neq i} D_{j t-1}^{A B}\right) D_{i t}\right)$

Total costs are displayed in Figure 11.

Hotspot and full PES schemes are always the least cost options amongst the four policy options. ${ }^{25}$ In a clustered case, the CA policy is the most costly option. This can be explained by the fact that the CA policy requires to compensate the agent for its whole payoff in order to conserve its land, while hotspot and full PES schemes are implemented on a voluntary basis, therefore distributing the cost of the policy more efficiently.

\footnotetext{
${ }^{25}$ We focus here on direct costs, and avoid to consider transaction costs, which may be very high for PES implementation.
} 
In a dispersed case, the $\mathrm{AB}$ policy is the most costly policy option. This is because $\underline{X}$-agents receive neither a PES payment nor an agglomeration bonus. It follows that controlling leakage is more costly in this case. Moreover, stronger interactions increase the variability of the results across time.

$* * * * *$ Figure Costs here $* * * * * * * * *$

\subsubsection{Cost effectiveness}

To complete our policy comparisons, we present some cost effectiveness results of our simulations. We consider first the level of avoided deforestation per unit cost (Figure 12): $A D_{t} / C_{t}$. One can see here that PES are the most cost-effective tools. In contrast, CA tends to be the least cost-effective option, except for the dispersed case and especially with high interactions. This result is in line with the literature arguing that policies relying on price signals (such as PES) are more efficient than command-and-control policies (such as $\mathrm{CA}$ ). AB policy brings an intermediate cost-efficiency.

We also consider the level of leakage per unit cost, $L_{t} / C_{t}$ (Figure 13). In this case, PES schemes are the policies that result in the highest level of leakage per unit cost. In contrast, lower levels of leakage are associated with $\mathrm{CA}$ and $\mathrm{AB}$ policies per unit spent in the policy. In particular, a $\mathrm{CA}$ policy option counterbalances to some extent the lack of price efficiency in the dispersed case with high interactions. This result brings an interesting insight: policies that appear to be the most cost-effective at the project level may result in high levels of leakage, reducing the effectiveness of the policy at a landscape level.

***** Figure Avoided deforestation per unit costs here $* * * * * * * * *$

***** Figure Leakage per unit costs here ${ }^{* * * * * * * * *}$

\section{Conclusion}

Governments in LMICs that engage in REDD+ initiatives typically implement avoided deforestation and forest degradation policies that may directly or indirectly influence the drivers of forest loss. A key concern that has been extensively voiced is that efforts to reduce forest loss in one location may result in deforestation and forest degradation being displaced to another location, that is leakage. Indeed, leakage is a frequently mentioned as a shortcoming of REDD+ implementation, both at the local and the international levels. In this paper, we consider several avoided deforestation policy options, explicitly addressing avoided deforestation, leakage and the costs of the policy. 
We apply our analysis to different spatial landscapes whilst expanding the definition of leakage by considering both treated and non treated zones, that depicts what is at stake both within and outside policy intervention adjacent areas. Our paper makes to make several contributions to the existing literature on the design of policies for forest conservation. Several interesting findings can be found from our analytical model and simulations.

First, leakage is sensitive to the interaction of the specific REDD+ policy and the spatial distribution of forest patch types. For example, our model suggests that the efficacy of a conservation area depends critically on whether the landscape is homogeneous (clustered) or heterogeneous (dispersed). In the former case, our model predicts the highest level of leakage compared to the other policies addressed in the latter there is the least leakage. Under a targeted hotspot PES policy, the spatial distribution of leakage depends again on whether forest patches of the same type are clustered or dispersed.

Second, the targeted hotspot and non-targeted full PES policy schemes are the least cost option for reducing deforestation; and are the most effective tool in terms of avoided deforestation under a fixed budget. It follows that if the policy maker sets its short-term objective in terms of level of avoided deforestation at the landscape scale depends again on whether forest patches of the same type are clustered or dispersed (AB) and conservation area (CA) policies are best in a clustered case and a dispersed case respectively. However, PES schemes are most effective if the policy maker objective is to minimise costs of avoided deforestation at the policy landscape, whilst ignoring leakage.

Finally, we show that the intensity of the interactions unambiguously tend to increase the variability over time of the avoided deforestation at the landscape scale. This result gives the insight that avoided deforestation policies need to be assessed in the long run, with sufficiently long periods of observation, in order to avoid focusing on short-term episodes, particularly when interactions are strong. Though we model spatial analysis of deforestation with localized leakage, our analysis is relevant to any public good provision with spatial interactions in which the action of an agent has a direct impact on their neighbours' payoffs.

We conclude with two final observations. First, we assume perfect monitoring of deforestation. Yet in reality monitoring is costly, often imperfect, and monitoring costs most likely are a function of location. The spatial distribution of enforcement activities will in turn affect spatial spillovers, an important consideration for sizing and siting conservation areas (Robinson et al., 2011; Pfaff and Robalino, 2012; Sims, 2014). Second, forests provide a multitude of ecosystem services in addition to carbon sequestration. Habitat fragmentation in particular affects the ability of forested areas to 
provide biodiversity benefits (Pfaff and Robalino, 2012; Sims, 2014). Our model can be adapted to address such issues of both total forest cover and contiguous spatial patterns.

\section{Acknowledgements}

The Laboratoire d'Économie Forestière (LEF) contributes to the LabEx ARBRE ANR-11LABX-0002-01. This paper has been presented at the 2014 FAERE Conference (Montpellier, France), the 2014 ENRMDTE Conference (Clermont-Ferrand, France) and the 2015 EAERE Conference (Helsinki, Finland). We thank the participants for their valuable comments.

\section{Appendix A. Set of leakage situations}

Our patch specification and our reduced form for deforestation profit are designed to fit a variety of cases where leakage can take place. Yet, diverse interpretations of our model can be made.

\section{Appendix A.1. Local market-based leakage}

Consider here that each patch represents one agent's unit of land in the landscape. We assume that all agents sell their products on the same market. Thus, the price at which they sell the products from deforestation is: $p\left(D_{t}\right)$. The profit from deforestation by agent $i$ can thus be written:

$$
\pi_{i t}=p\left(D_{t}\right) D_{i t}-c\left(D_{i t}\right)
$$

As long as larger supply tends to decrease the price of products $\left(\frac{\partial p}{\partial D_{t}}<0\right)$, this problem can be reduced as in Equation (1). In this case, $\alpha_{i j}$ can be considered as an indicator of the price elasticity of demand. If all agents have the same access to markets and the same supply influence, one can consider that $\alpha_{i j}=\alpha, \forall i, j$. Yet, one can consider that the law of unique price may not hold, this is why we keep potentially heterogeneous $\alpha_{i j}$. Indeed, reduced deforestation due to the implementation of a policy option for example is likely to increase nearby deforestation when product markets are not functioning efficiently, but have no local impact when markets are efficient. This case is developed in Robinson et al. (2011).

By extension, the model would also fit with international market-based leakage. In this case, consider that one patch is a country, and that the land-use decision is made by one representative agent. Here again, $\alpha_{i j}$ is an indicator of the price elasticity of demand, and the heterogeneity between the $\alpha_{i j}$ depends on the level of market integration: poor market integration may mean that only close neighbours will have an impact on the price in region $i$, while perfect market 
integration would come with a unique price (and thus homogeneous spatial interactions) within the set of countries.

\section{Appendix A.2. Activity-shifting leakage}

Consider here that each patch represents one agent's unit of land and suppose that households can migrate from one patch to adjacent patches. One possible mechanism for a localized leakage could be whereby reduced deforestation in one patch following the implementation of a policy option results in less agricultural land than there would otherwise be, and thus decreased demand for agricultural labourers in that patch, leading to localized out-migration to adjacent patches which then experience a surfeit of agricultural labourers relative to the status quo, making agriculture more attractive and thus increasing deforestation. Reduced labour demand in one patch has an influence on the labour supply and thus labour cost in its neighbourhood with depressing wages, which somehow comes back to Equation (1).

By extension, the model would also fit with regards to a within-property situation that is more conventional that the previous situation in terms of activity-shifting leakage. In this case, consider that only one agent owns all the patches of the landscape. His goal may be to allocate labour between all patches in order to maximize his expected profit. As long as our agent has poor access to labour markets, the allocation of labour in any patch $j$ has an influence on labour allocated to patch $i$, and thus on his expected profit: there is an opportunity cost of allocating labour in $i$ instead of $j$. In this case, $\alpha_{i j}$ can be considered as an indicator of transport costs from patch $i$ to patch $j$. This case is developed in Delacote and Angelsen (2015).

\section{Appendix B. Results from the specified form}

\section{Appendix B.1. PESh policy}

In our specified framework, agent $i$ 's deforestation under the PESh policy is:

$$
\begin{aligned}
D_{i t}^{P E S h} & =\beta \bar{X}_{i t}-\sum_{j \neq i} \alpha_{i j} D_{j t-1}^{P E S h}-p_{h}, \forall i \in[\bar{X}] \\
D_{i t}^{P E S h} & =\beta \underline{X}_{i t}-\sum_{j \neq i} \alpha_{i j} D_{j t-1}^{P E S h}, \forall i \in[\underline{X}]
\end{aligned}
$$

The avoided deforestation and leakage at the landscape scale following the PESh policy implementation are then:

$$
A D_{t}^{P E S h}=\sum_{i \in \bar{X}} p_{h}-\sum_{i}\left[\sum_{j \neq i} \alpha_{i j}\left(D_{j t-1}^{*}-D_{j t-1}^{P E S h}\right)\right]
$$




$$
L_{t}^{P E S h}=\sum_{i \in \bar{X}} p_{h}-\sum_{i}\left[\sum_{j \neq i} \alpha_{i j}\left(D_{j t-1}^{*}-D_{j t-1}^{P E S h}\right)\right]-\left(\sum_{i \in \bar{X}} p_{h}-\sum_{i}\left[\sum_{j \neq i} \alpha_{i j}\left(D_{j 0}^{*}-D_{j 0}^{P E S h}\right)\right]\right)
$$

\section{Appendix B.2. PESf policy}

In our specified framework, agent $i$ 's deforestation under the PESf policy is:

$$
D_{i t}^{P E S f}=\beta X_{i t}-\sum_{j \neq i} \alpha_{i j} D_{j t-1}^{P E S f}-p_{f}, \forall i \in[\underline{X}, \bar{X}]
$$

The avoided deforestation and leakage at the landscape scale following the PESf policy implementation are then:

$$
\begin{gathered}
A D_{t}^{P E S f}=\sum_{i}\left[p_{f}-\left(\sum_{j \neq i} \alpha_{i j}\left(D_{j t-1}^{*}-D_{j t-1}^{P E S f}\right)\right)\right] \\
L_{t}^{P E S f}=\sum_{i}\left[p_{f}-\left(\sum_{j \neq i} \alpha_{i j}\left(D_{j t-1}^{*}-D_{j t-1}^{P E S f}\right)\right)\right]-\left(\sum_{i}\left[p_{f}-\left(\sum_{j \neq i} \alpha_{i j}\left(D_{j 0}^{*}-D_{j 0}^{P E S f}\right)\right)\right]\right)
\end{gathered}
$$

\section{Appendix B.3. CA policy}

In our specified framework, agent $i$ 's deforestation under the CA policy is:

$$
\begin{aligned}
& D_{i t}^{C A}=0, \forall i=\tilde{i} \\
& D_{i t}^{C A}=\beta X_{i t}-\sum_{j \neq i} \alpha_{i j} D_{j t-1}^{C A}, \quad \forall i \neq \tilde{i}
\end{aligned}
$$

The avoided deforestation and leakage at the landscape scale following the CA policy implementation are then:

$$
\begin{gathered}
A D_{t}^{C A}=D_{\tilde{i} t}^{*}-\sum_{i}\left[\sum_{j \neq i} \alpha_{i j}\left(D_{j t-1}^{*}-D_{j t-1}^{C A}\right)\right] \\
L_{t}^{C A}=-\sum_{i}\left[\sum_{j \neq i} \alpha_{i j}\left(D_{j t-1}^{*}-D_{j t-1}^{C A}\right)+\sum_{j \neq i} \alpha_{i j}\left(D_{j 0}^{*}-D_{j 0}^{C A}\right)\right]
\end{gathered}
$$

\section{Appendix B.4. AB policy}

In our specified framework, agent $i$ deforestation under the AB policy is:

$$
\begin{aligned}
D_{i t}^{A B} & =\beta \bar{X}_{i t}-(1-b) \sum_{j \neq i} \alpha_{i j} D_{j t-1}^{A B}-a, \forall i \in[\bar{X}] \\
D_{i t}^{A B} & =\beta \underline{X}_{i t}-\sum_{j \neq i} \alpha_{i j} D_{j t-1}^{A B}, \forall i \in[\underline{X}]
\end{aligned}
$$


The avoided deforestation and leakage at the landscape scale following the AB policy implementation are then:

$$
\begin{aligned}
A D_{t}^{A B} & =\sum_{i \in \bar{X}}\left[a-\left(\sum_{j \neq i} \alpha_{i j}\left(D_{j t-1}^{*}-D_{j t-1}^{A B}\right)-b D_{j t-1}^{A B}\right)\right] \\
& -\sum_{i \in \underline{X}}\left[\sum_{j \neq i} \alpha_{i j}\left(D_{j t-1}^{*}-D_{j t-1}^{A B}\right)\right] \\
L_{t}^{A B} & =\sum_{i \in \bar{X}}\left[a-\left(\sum_{j \neq i} \alpha_{i j}\left(D_{j t-1}^{*}-D_{j t-1}^{A B}\right)-b D_{j t-1}^{A B}\right)\right] \\
& -\sum_{i \in \underline{X}}\left[\sum_{j \neq i} \alpha_{i j}\left(D_{j t-1}^{*}-D_{j t-1}^{A B}\right)\right] \\
& -\left(\sum_{i \in \bar{X}}\left[a-\left(\sum_{j \neq i} \alpha_{i j}\left(D_{j 0}^{*}-D_{j 0}^{A B}\right)-b D_{j 0}^{A B}\right)\right]\right. \\
& \left.-\sum_{i \in \underline{X}}\left[\sum_{j \neq i} \alpha_{i j}\left(D_{j 0}^{*}-D_{j 0}^{A B}\right)\right]\right)
\end{aligned}
$$

\section{Appendix C. Simulation parameters}

\section{Appendix C.1. Parameter values}

\begin{tabular}{cc}
\hline Parameter & Value \\
\hline$\beta$ & 1 \\
$\bar{X}$ & 5 \\
$\underline{X}$ & 0 \\
$\underline{\alpha}$ & 0.05 \\
$\bar{\alpha}$ & 0.1 \\
\hline
\end{tabular}


Appendix C.2. Policy calibration: same avoided deforestation at $t=1$

\begin{tabular}{ccccc}
\hline Parameter & $\mathrm{C} / \mathrm{L}$ & $\mathrm{C} / \mathrm{H}$ & $\mathrm{D} / \mathrm{L}$ & $\mathrm{D} / \mathrm{H}$ \\
\hline$p_{h}$ & 0.327 & 0.295 & 0.3654 & 0.3465 \\
$p_{f}$ & 0.17 & 0.14 & 0.19 & 0.18 \\
$a$ & 0.409 & 0.443 & 0.433 & 0.433 \\
$b$ & 0.0059 & 0.0059 & 0.0059 & 0.0059 \\
\hline$b_{1}$ & 0.003 & & & \\
$b_{2}$ & 0.00586 & & & \\
$b_{3}$ & 0.007 & & & \\
$b_{4}$ & 0.009 & & & \\
\hline
\end{tabular}

\section{Figures}


Figure 1: Expanding the concept of leakage

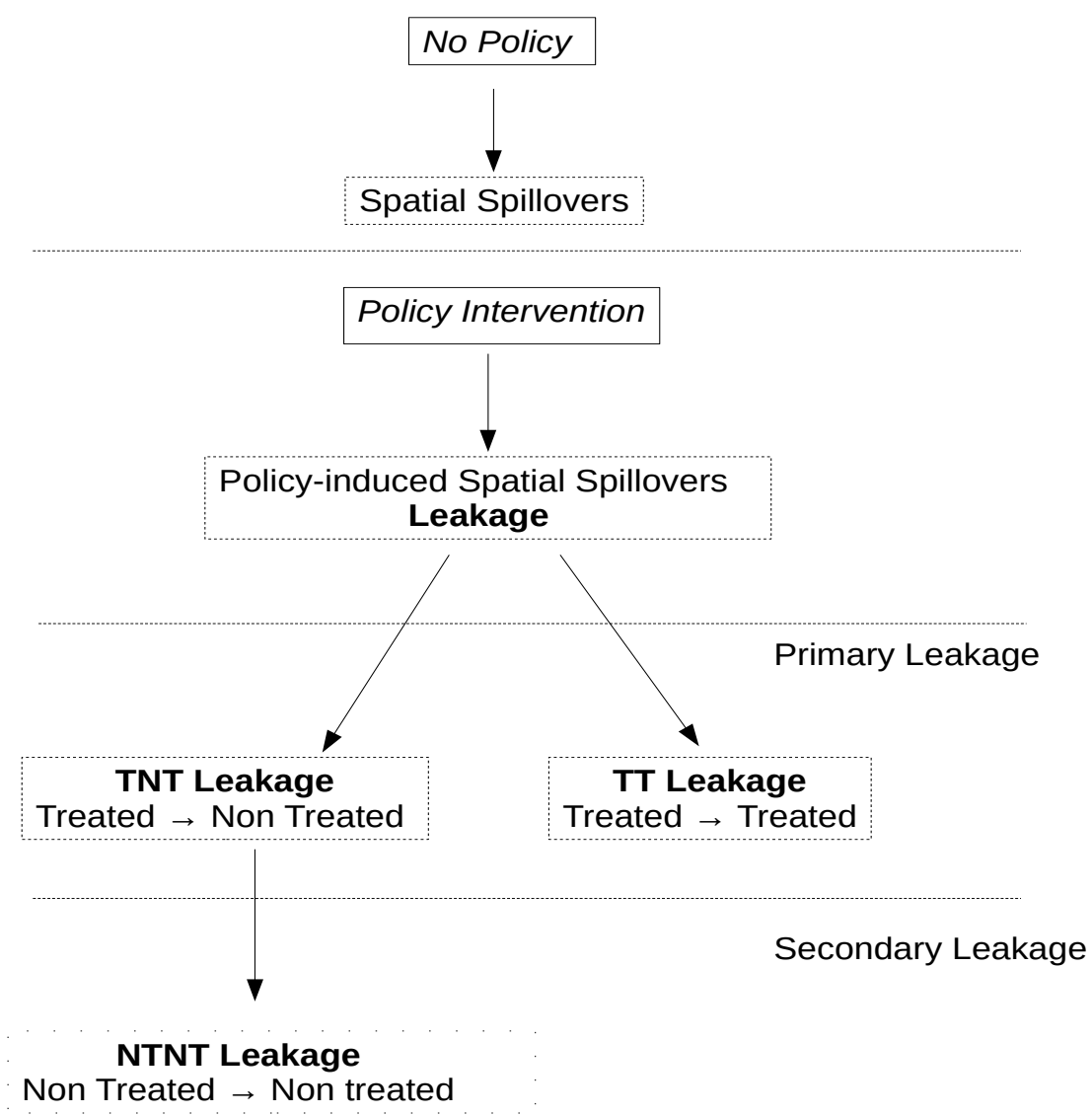


Figure 2: Business-as-usual deforestation dynamics

\section{Deforestation Intensity}

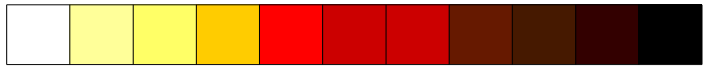

BAU deforestation in the clustered case with low interactions
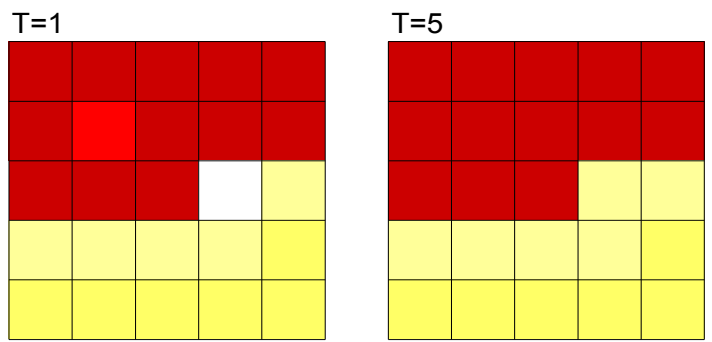

$\mathrm{T}=10$

BAU deforestation in the clustered case with high interactions
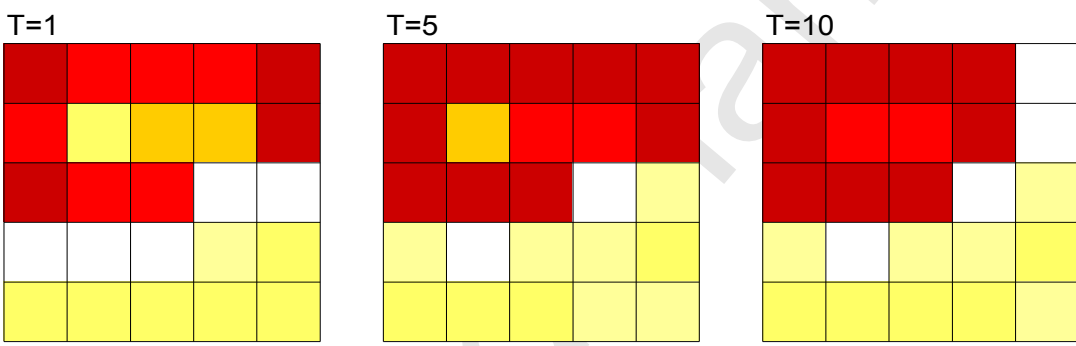

BAU deforestation in the dispersed case with low interactions
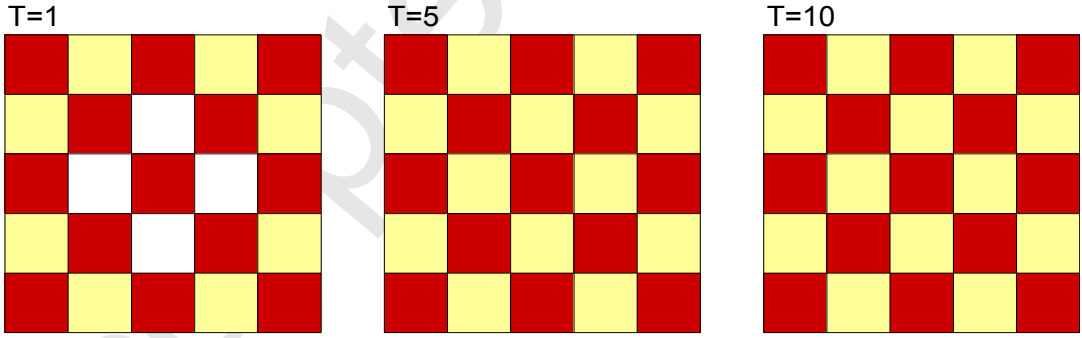

BAU deforestation in the dispersed case with high interactions
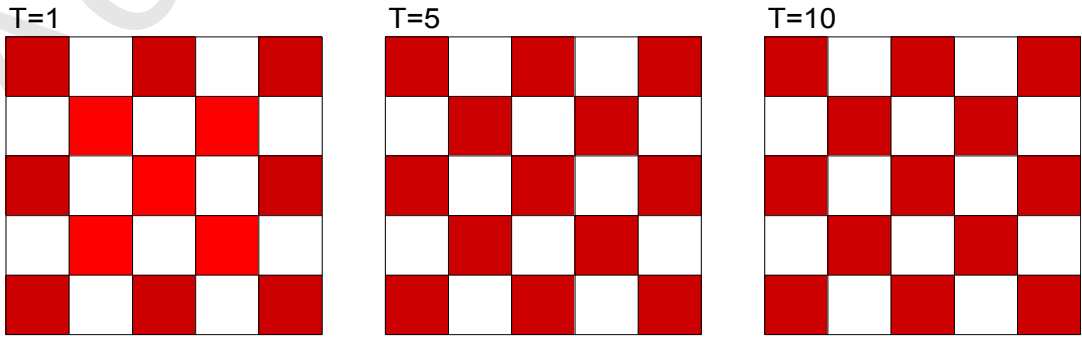
Figure 3: Leakage comparison between the $\bar{X}$-agents and $\underline{X}$-agents for the clustered case (left) and the dispersed case (right) (low interactions)
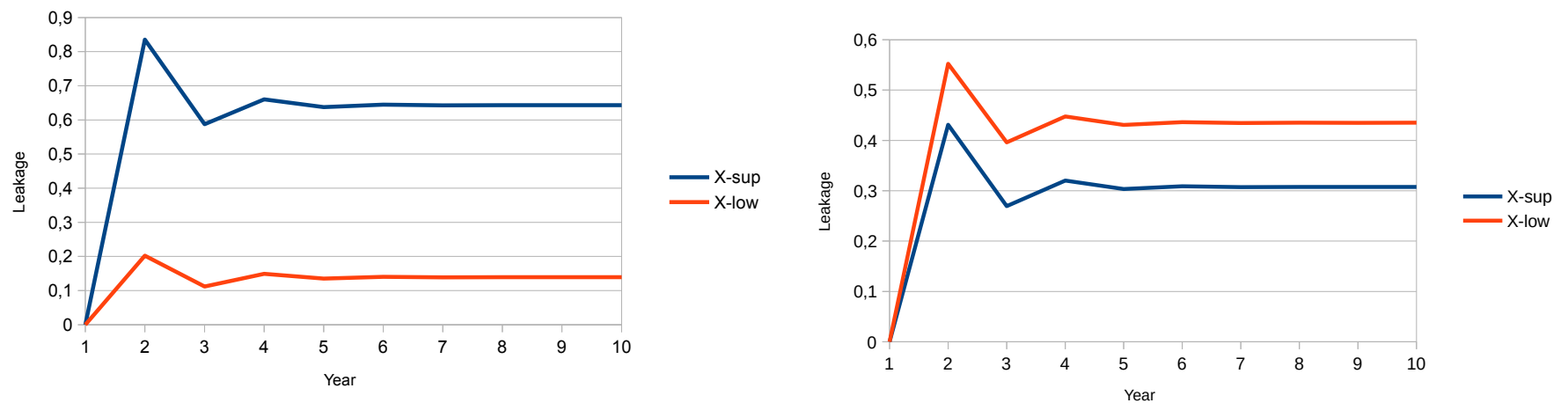

Figure 4: Leakage comparison between the full PES and the hotspot PES policies for $\bar{X}$-agents (left) and $\underline{X}$-agents (right) (low interactions/ clustered case)
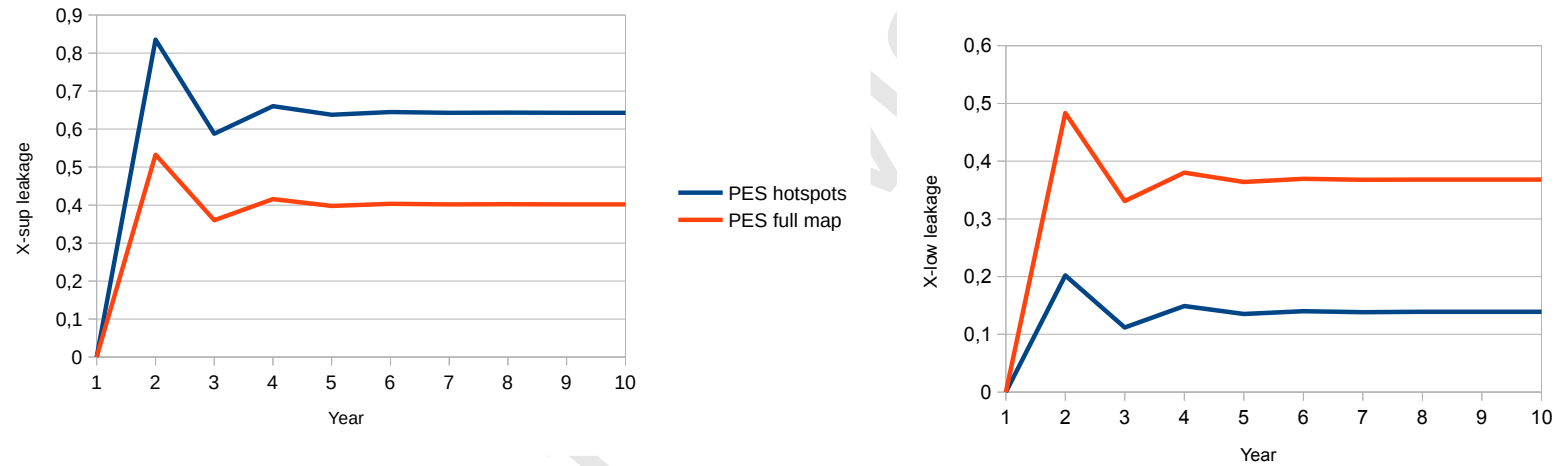

Figure 5: Leakage comparison between the full PES and the hotspot PES policies for the clustered case (left) and the dispersed case (right) (low interactions)
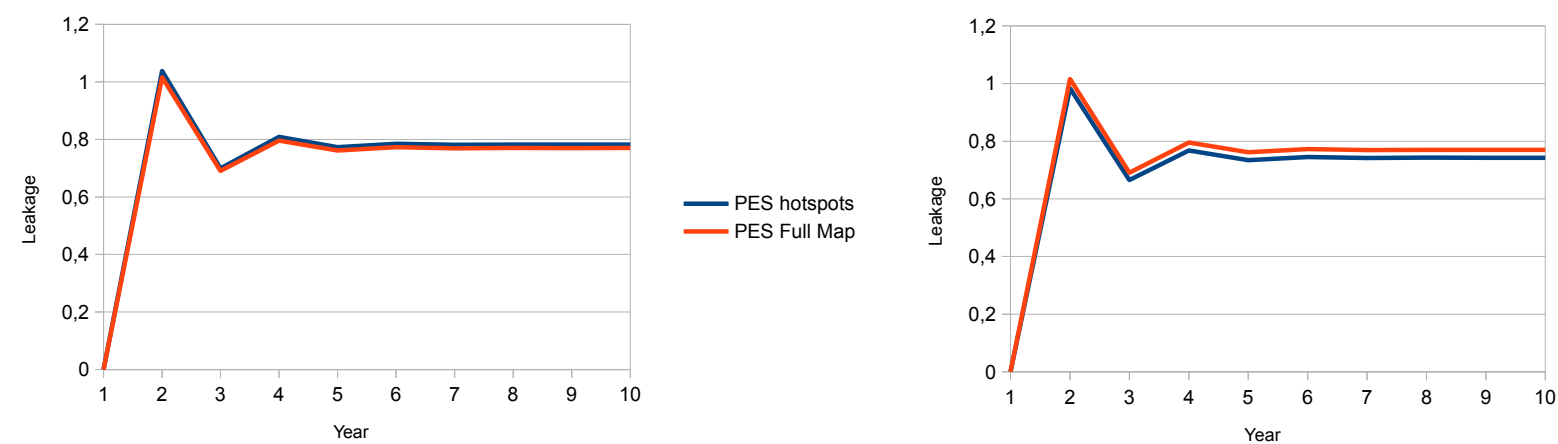
Figure 6: Leakage under the CA policy in the clustered case (low interactions)

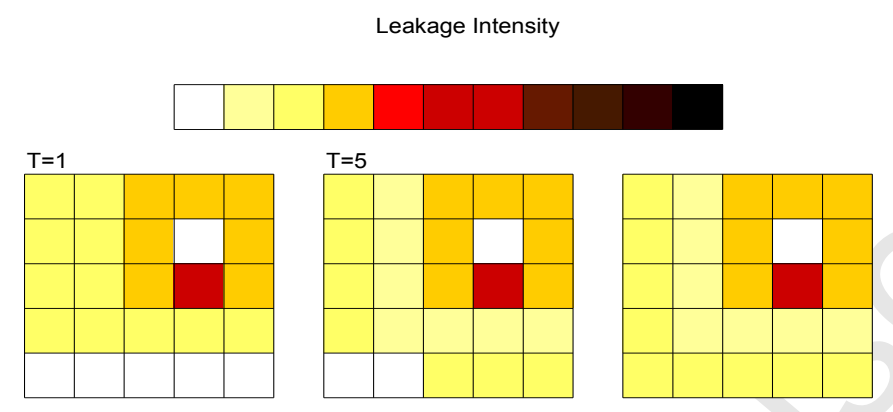

Figure 7: Leakage under the CA policy in the dispersed case (low interactions)

Leakage Intensity

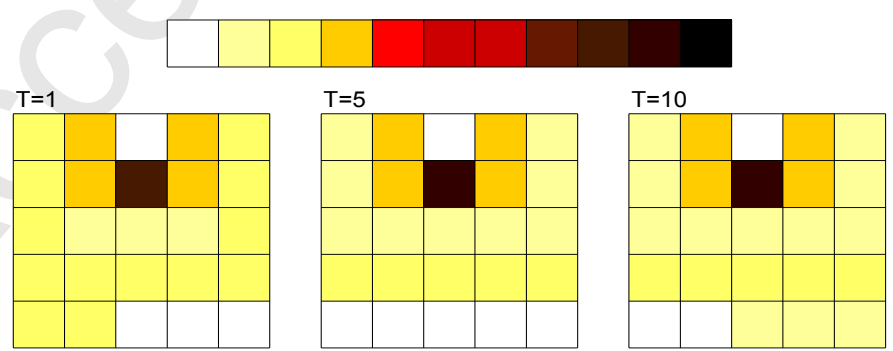


Figure 8: Leakage and avoided deforestation under the AB policy $\left(b_{1}<b_{2}<b_{3}<b_{4}\right.$ ) (low interactions/ dispersed case)
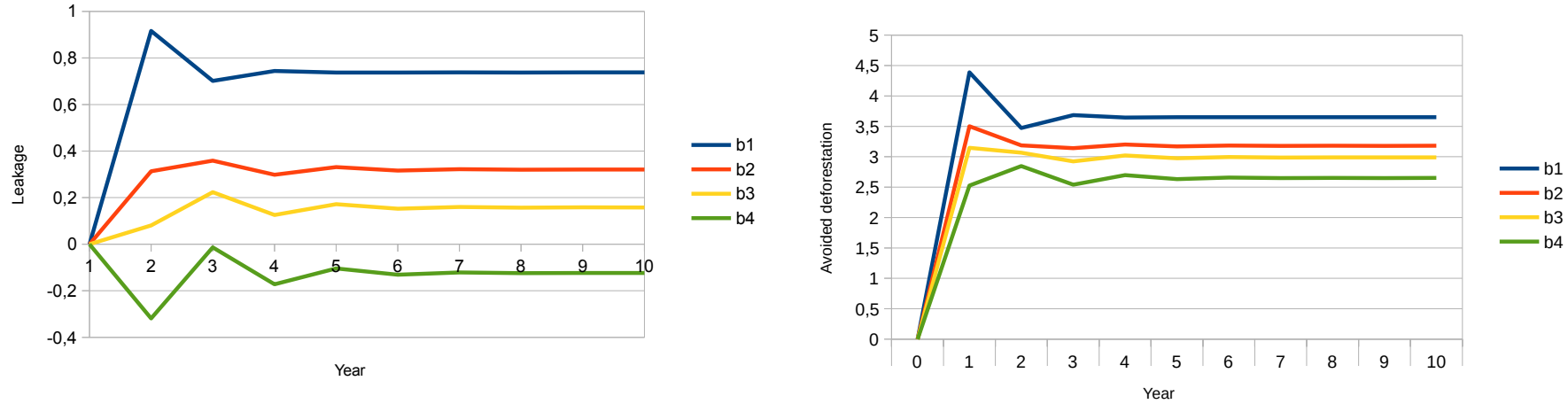

Figure 9: Avoided deforestation at the landscape scale

Clustered/ Low Interactions

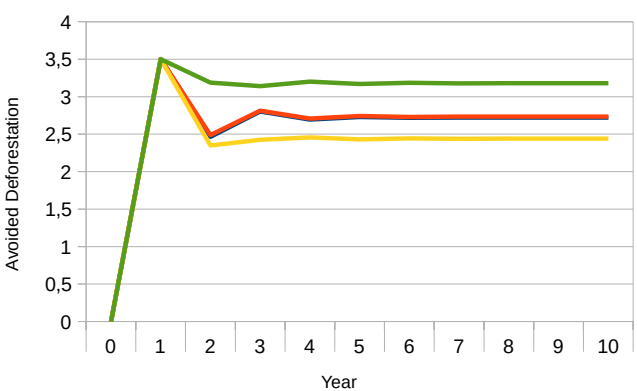

Dispersed/ Low Interactions

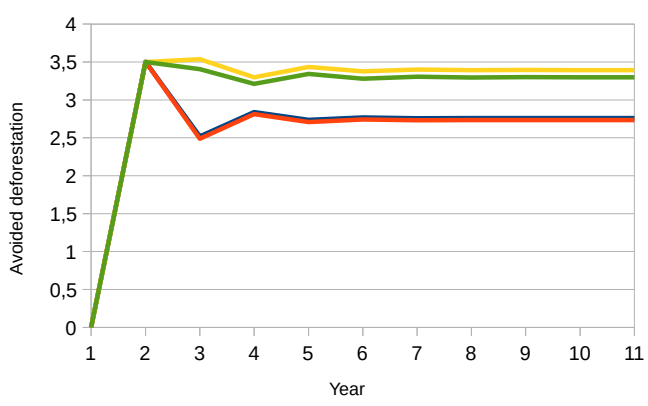

Clustered/ High Interactions

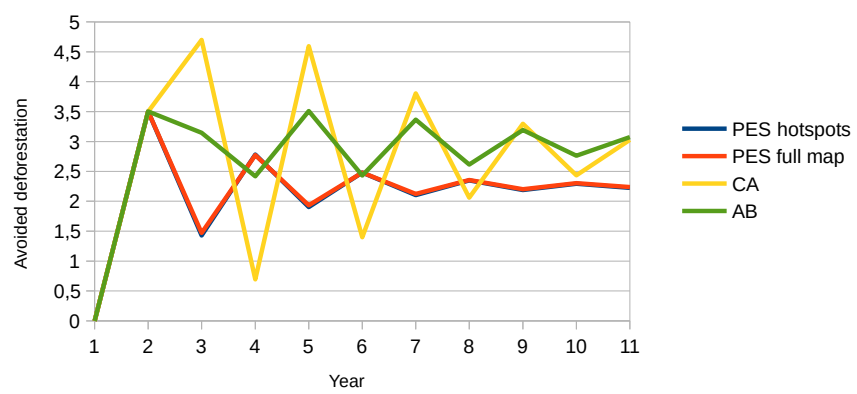

Dispersed/ High Interactions

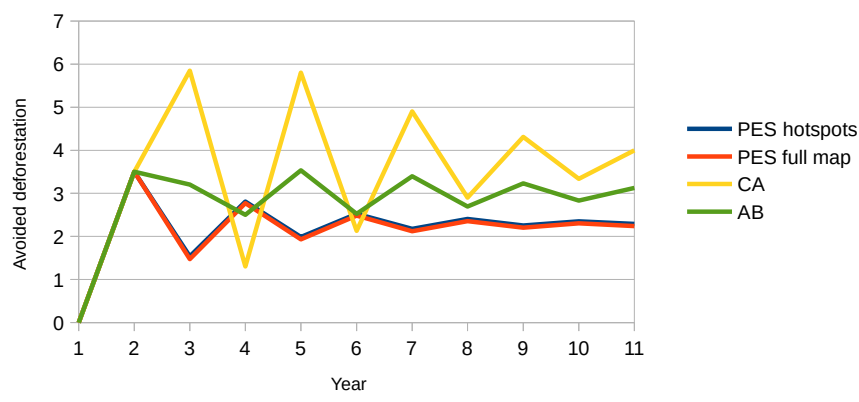


Figure 10: Leakage at the landscape scale

Clustered/ Low Interactions

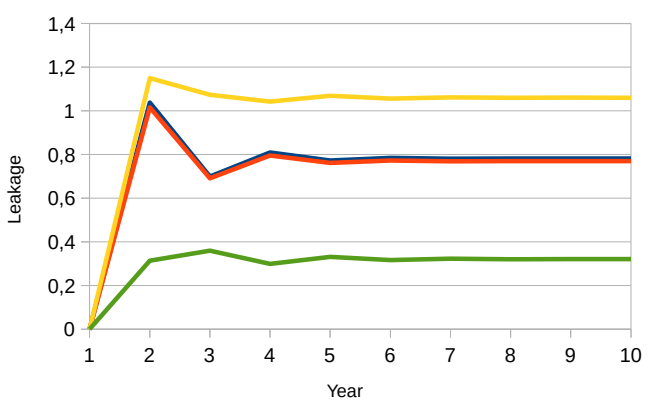

Dispersed/ Low Interactions

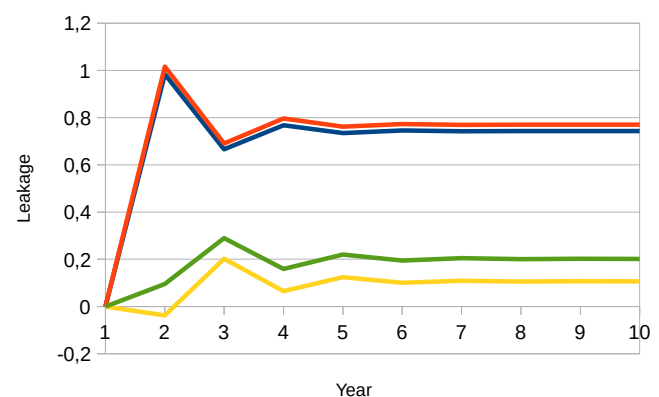

Clustered/ High Interactions

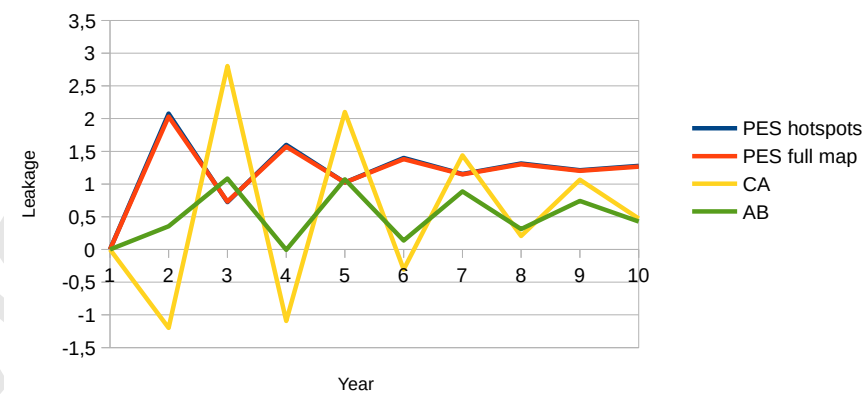

Dispersed/ High Interactions

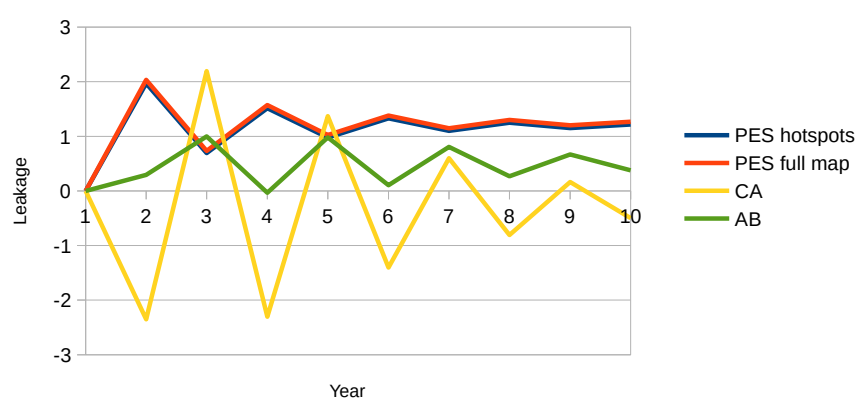




\section{Figure 11: Costs}

Clustered/ Low Interactions

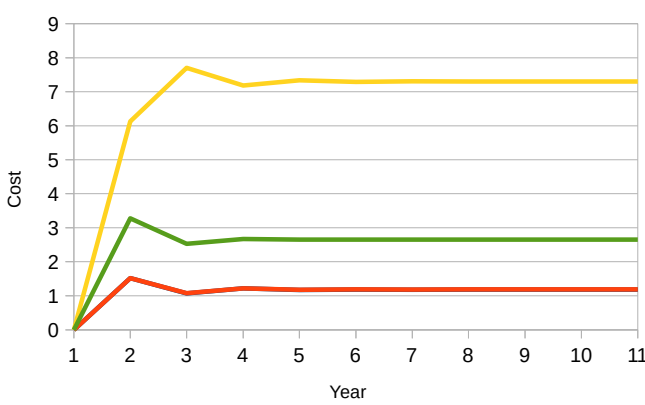

Dispersed/ Low Interactions

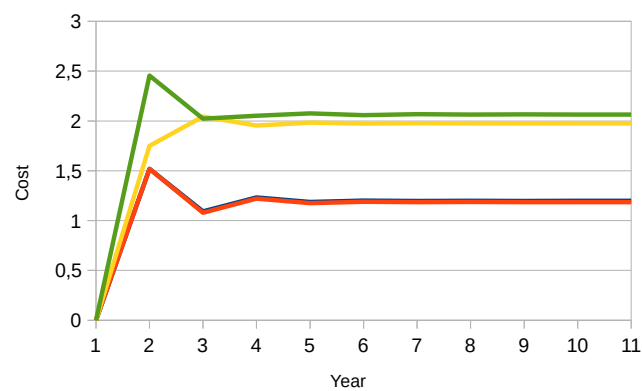

Clustered/ High Interactions

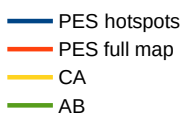

- PES hotspot - PES full map CA

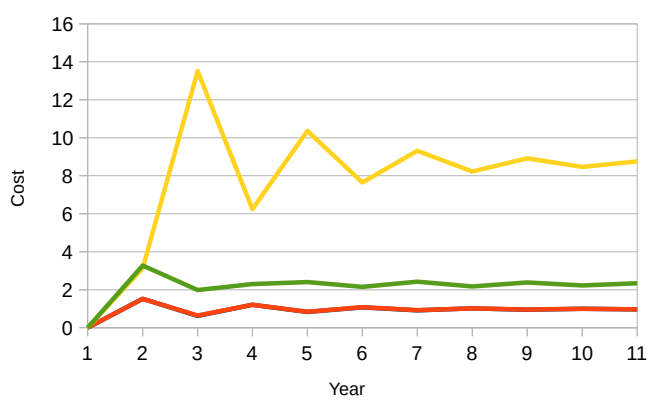

Dispersed/ High Interactions

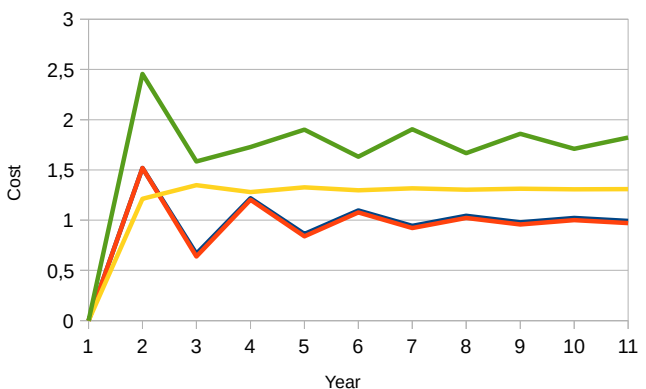

- PES hotspot PES full ma AB

- PES hotspots PES full map CA 
Figure 12: Avoided deforestation per unit costs

Clustered/ Low Interactions

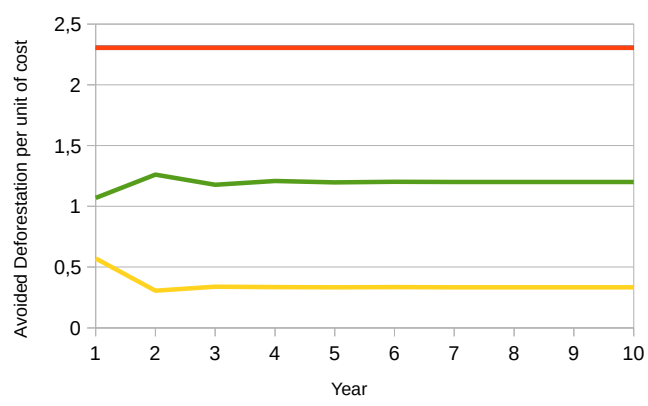

Dispersed/ Low Interactions

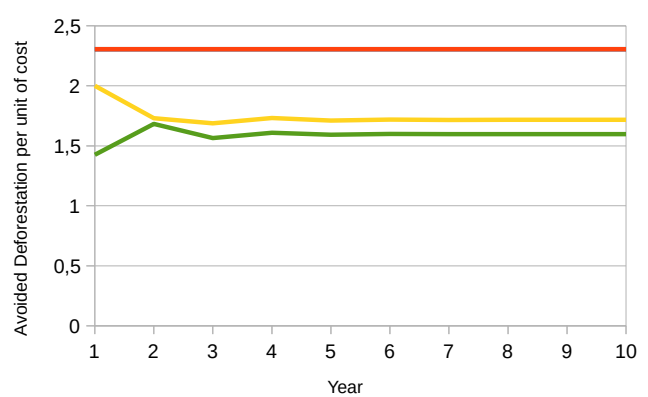

Clustered/ High Interactions

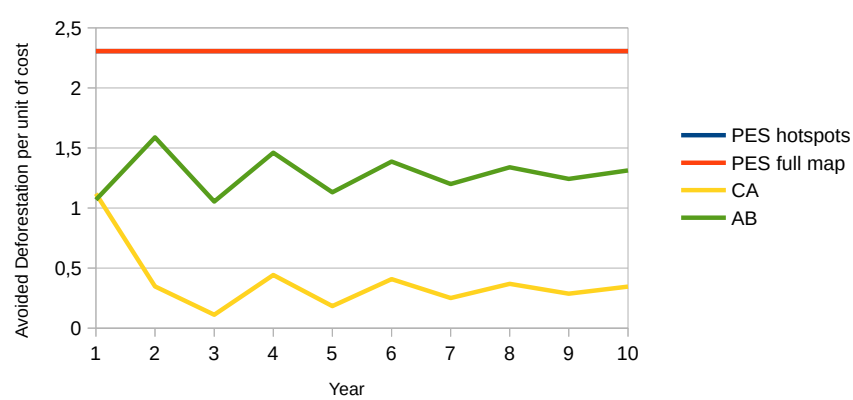

Dispersed/ High Interactions

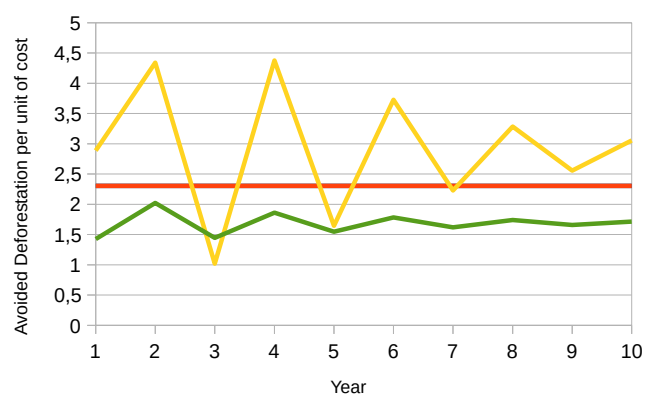

PES hotspots PES full map - CA 
Figure 13: Leakage per unit costs

Clustered/ Low Interactions

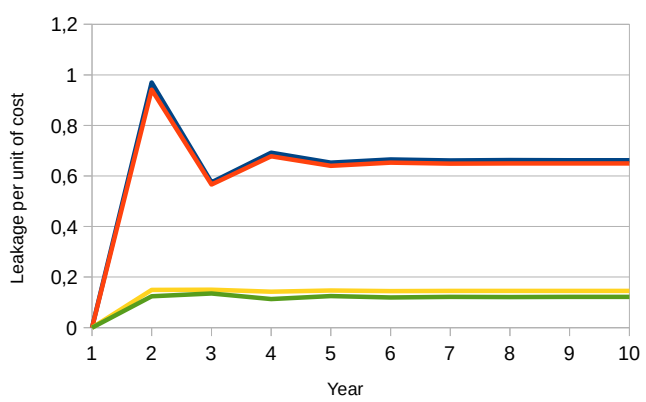

Dispersed/ Low Interactions

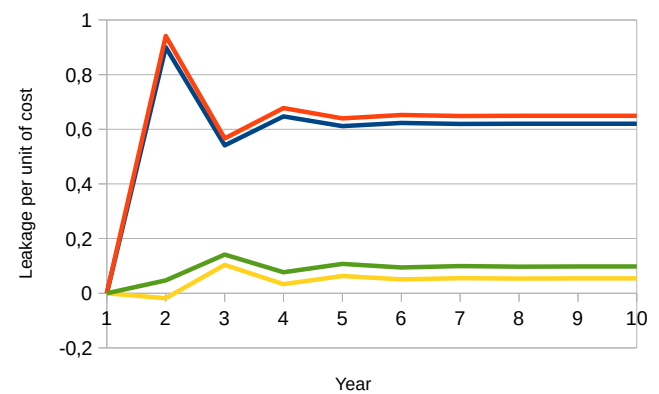

Clustered/ High Interactions

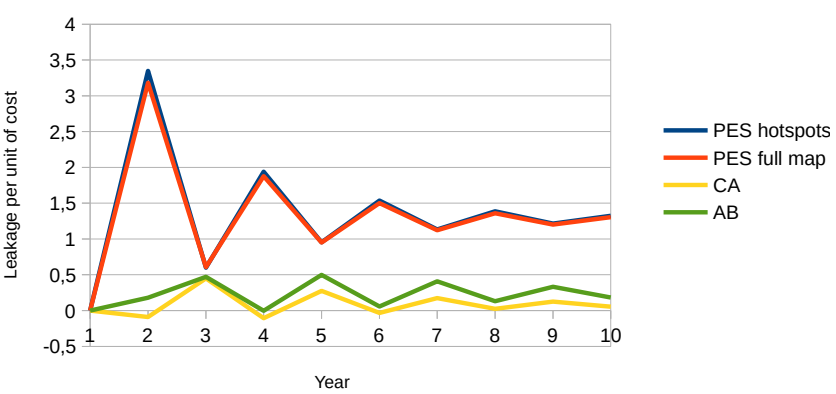

Dispersed/ High Interactions

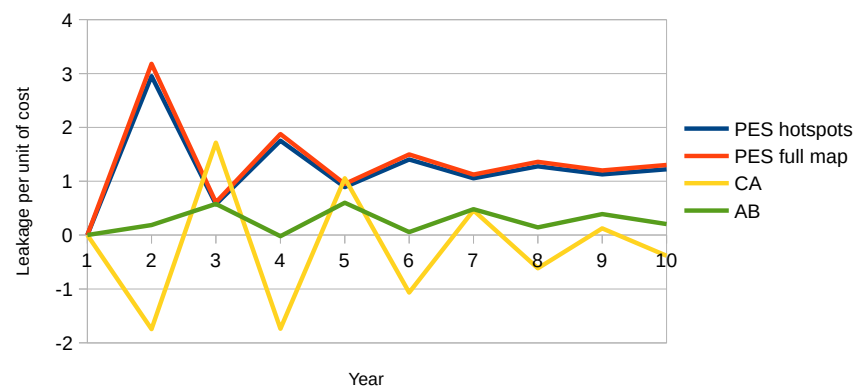




\section{References}

[1] Albers H.J., Robinson E.J.Z., 2013. Reducing Emissions from Deforestation and Forest Degradation. In: Shogren, J.F., (ed.) Encyclopedia of Energy, Natural Resource, and Environmental Economics, Vol. 2, pp. 78-85 Amsterdam: Elsevier.

[2] Alix-Garcia J., Wolff H., 2014. Payment for Ecosystem Services from Forests, Annual Review of Resource Economics. 6(1), 361-380.

[3] Alix-Garcia J., Shapiro E.N., Sims K.R., 2012. Forest Conservation and Slippage: Evidence from Mexico's National Payments for Ecosystem Services Program, Land Economics. 88(4), 613-638.

[4] Amin A., Choumert J., Combes J.-L., Combes-Motel P., Kéré E., Ongono-Olinga J., Schwartz S., 2014. A Spatial Econometric Approach to Spillover Effects between Protected Areas and Deforestation in the Brazilian Amazon, Working Papers 201406, CERDI.

[5] Armsworth P.R., Gretchen D.C., Kareiva P., Sanchirico J.N., 2006. Land Market Feedbacks can Undermine Biodiversity Conservation. Proceedings of the National Academy of Sciences of the United States of America (PNAS). 103(14), 5403-5408.

[6] Aukland L., Moura Costa P., Brown S., 2003. A Conceptual Framework and its Application for Addressing Leakage: the Case of Avoided Deforestation, Climate Policy. 3(2), 123-136.

[7] Baylis K., Fullerton D., Shah P., 2013. What Drives Forest Leakage?, Working Paper, Department of Agricultural and Consumer Economics, University of Illinois at Urbana-Champaign.

[8] Bond I., Grieg-Gran M., Wertz-Kanounnikoff S., Hazlwood P., Wunder S., Angelsen A., 2009. Incentives to Sustain Forest Ecosystem Services. A Review and Lessons for REDD. Natural Resources (16), International Institute for Environment and Development, CIFOR and World Resources Institute.

[9] Carbone J.C., 2013. Linking Numerical and Analytical Models of Carbon Leakage, American Economic Review. 103(3), 326-331.

[10] Delacote P., Angelsen A. 2015. Reducing Deforestation and Forest Degradation: Leakage or Synergy?, Land Economics, vol. 91(3), pages 501-515. 
[11] Gan J., McCarl B.A., 2007. Measuring Transnational Leakage of Forest Conservation, Ecological Economics. 64, 423-432.

[12] Honey-Roses J., Baylis K., Ramirez M.I., 2011. A Spatially Explicit Estimate of Avoided Forest Loss, Conservation Biology. 25(5), 1032-1043.

[13] Lichtenberg E., Smith-Ramirez R., 2011. Slippage in Conservation Cost Sharing, American Journal of Agricultural Economics. 93(1), 113-129.

[14] Meyfroidt P., Lambin E.F., 2009. Forest Transition in Vietnam and Displacement of Deforestation Abroad, Proceedings of the National Academy of Sciences of the United States of America (PNAS). 106(38), 16139-16144.

[15] Miteva D.A., Pattanayak S.K., Ferraro P.J., 2012. Evaluation of Biodiversity Policy Instruments: What Works and What Doesn't?, Oxford Review of Economic Policy. 28(1), 69-92.

[16] Murray B.C., 2008. Leakage from an Avoided Deforestation Compensation Policy: Concepts, Empirical Evidence, and Corrective Policy Options, Nicholas Institute for Environmental Policy Solutions, Duke University, Durham, North Carolina.

[17] Murray B.C., McCarl, B.A., Lee H., 2004. Estimating Leakage from Forest Carbon Sequestration Programs, Land Economics. 80(1), 109-124.

[18] van Oosterzee P., Blignaut J., Bradshaw C.J.A., 2012. iREDD Hedges against Avoided Deforestation's Unholy Trinity of Leakage, Permanence and Additionality, Conservation Letters. 5, 266-273.

[19] Oliveira P.J.C., Gregory P.A., Knapp D.E., Almeyda A., Galvan-Gildemeister R., Keene S., Raybin R.F., Smith R.C., 2007. Land-Use Allocation Protects the Peruvian Amazon, Science. $317,1233-1236$.

[20] Parkhurst G.M., Shogren J.F., 2008. Smart Subsidies for Conservation, American Journal of Agricultural Economics. 90(5), 1192-1200.

[21] Pfaff A., Robalino J., 2012. Protecting Forests, Biodiversity, and the Climate: Predicting Policy Impact to Improve Policy Choice, Oxford Review of Economic Policy. 28(1), 164-179.

[22] Robalino J., Pfaff A., 2012. Contagious Development: Neighbor Interactions in Deforestation, Journal of Development Economics. 97(2), 427-436. 
[23] Roberts M.J., Bucholtz S., 2005. Slippage in the Conservation Reserve Program or Spurious Correlation? A Comment, American Journal of Agricultural Economics. 87(1), 244-250.

[24] Robinson E.J.Z., Albers H.J., Williams J.C., 2011. Sizing Reserves within a Landscape: the Roles of Villagers' Reactions and the Ecological-Socioeconomic Setting, Land Economics. 87(2), 233-249.

[25] Rosendahl K.E., Strand J., 2011. Carbon Leakage from the Clean Development Mechanism, The Energy Journal. 32(4), 27-50.

[26] Sauquet A., Marchand S., Féres J.G., 2014. Protected Areas, Local Governments, and Strategic Interactions: The Case of the ICMS-Ecologico in the Brazilian State of Parana, Ecological Economics. 107, 249-258.

[27] Schwarze E., Niles J.O., Olander J., 2002. Understanding and Managing Leakage in ForestBased Greenhouse-Gas-Mitigation Projects, Philosophical Transactions of the Royal Society A. 360(1797), 1685-1703.

[28] Sims K.R., 2014. Do Protected Areas reduce Forest Fragmentation? A Microlandscapes Approach, Environmental and Resource Economics. 58(2), 303-333.

[29] Wätzold F., Drechsler M., 2014. Agglomeration Payment, Agglomeration Bonus or Homogeneous Payment?, Resource and Energy Economics. 37, 85-101.

[30] Wear D.N., Murray B.C., 2004. Federal Timber Restrictions, Interregional Spillovers, and the Impact on US Softwood Markets, Journal of Environmental Economics and Management. 47(2), 307-330.

[31] Wu J., 2000. Slippage Effects of the Conservation Reserve Program, American Journal of Agricultural Economics. 82(4), 979-992.

[32] Wu J., Zilberman D., Babcock B.A., 2001. Environmental and Distributional Impacts of Conservation Targeting Strategies, Journal of Environmental Economics and Management. 41(3), 333-350.

[33] Wunder S., 2008. How do we deal with Leakage? in Angelsen A., Moving ahead with REDD: Issues, Options and Implications, CIFOR. Chapter 7, 65-76. 
Clustered/ Low Interactions

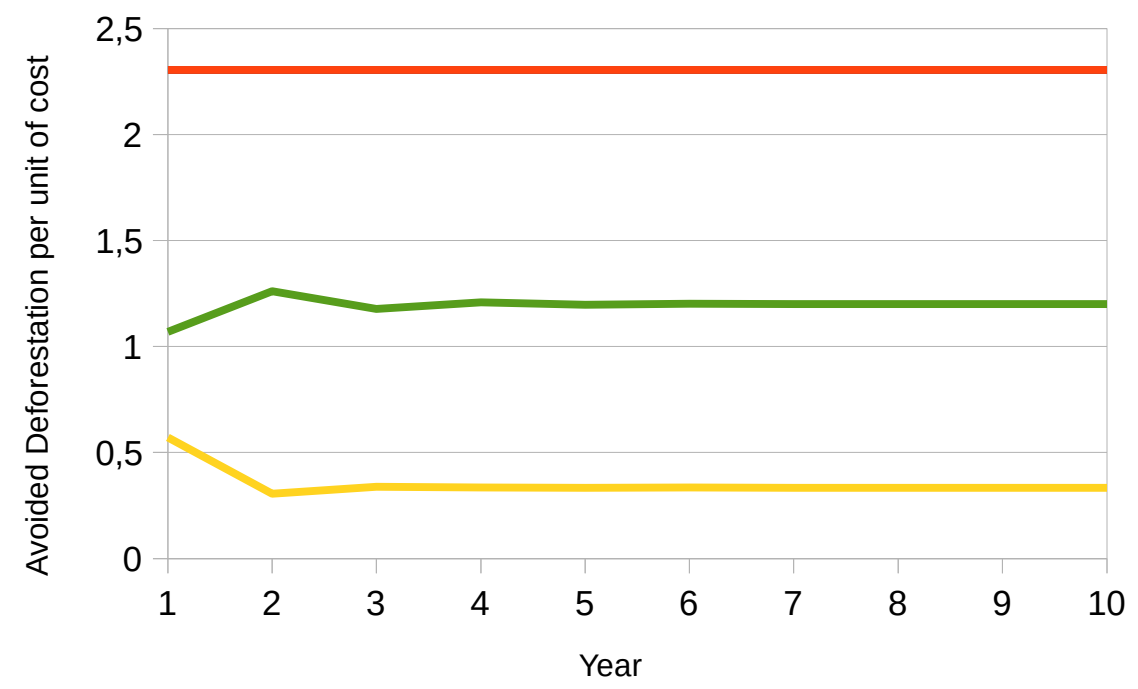




\section{Clustered/ High Interactions}

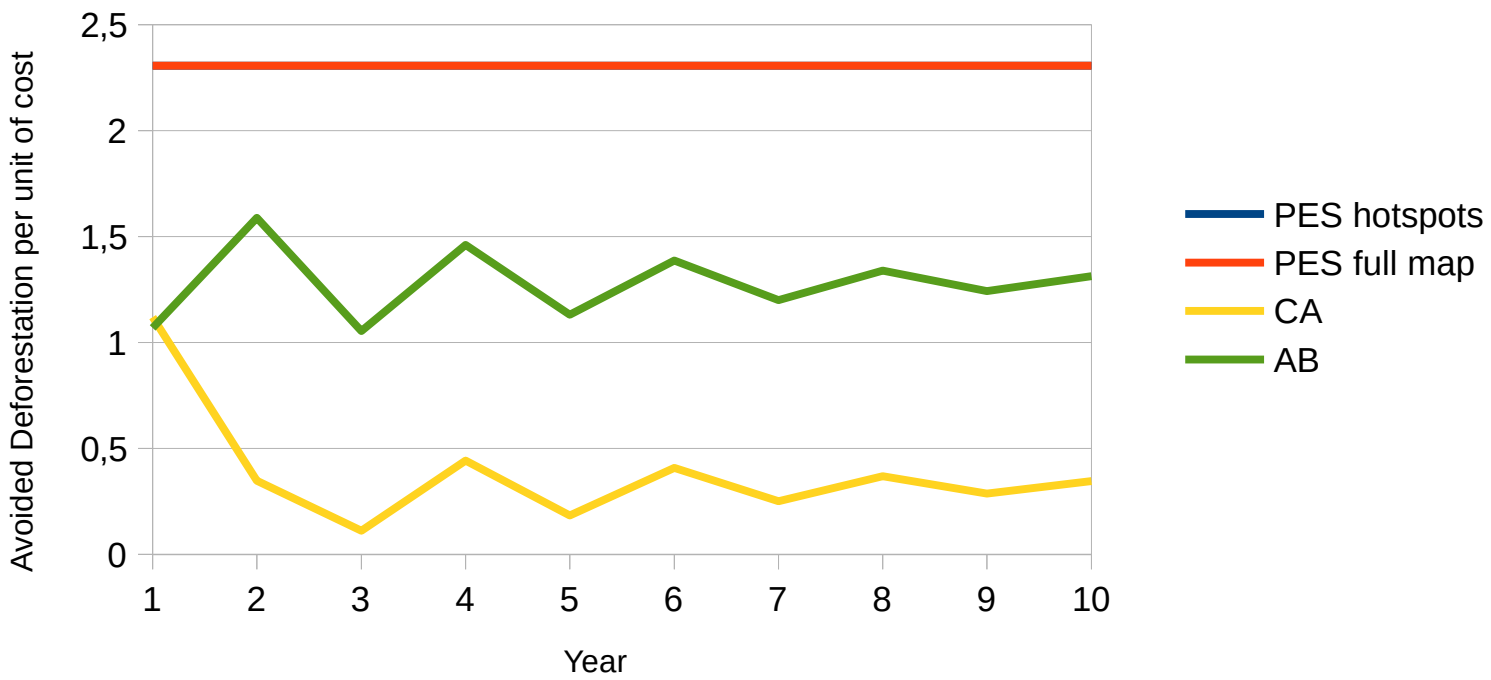




\section{Dispersed/ Low Interactions}

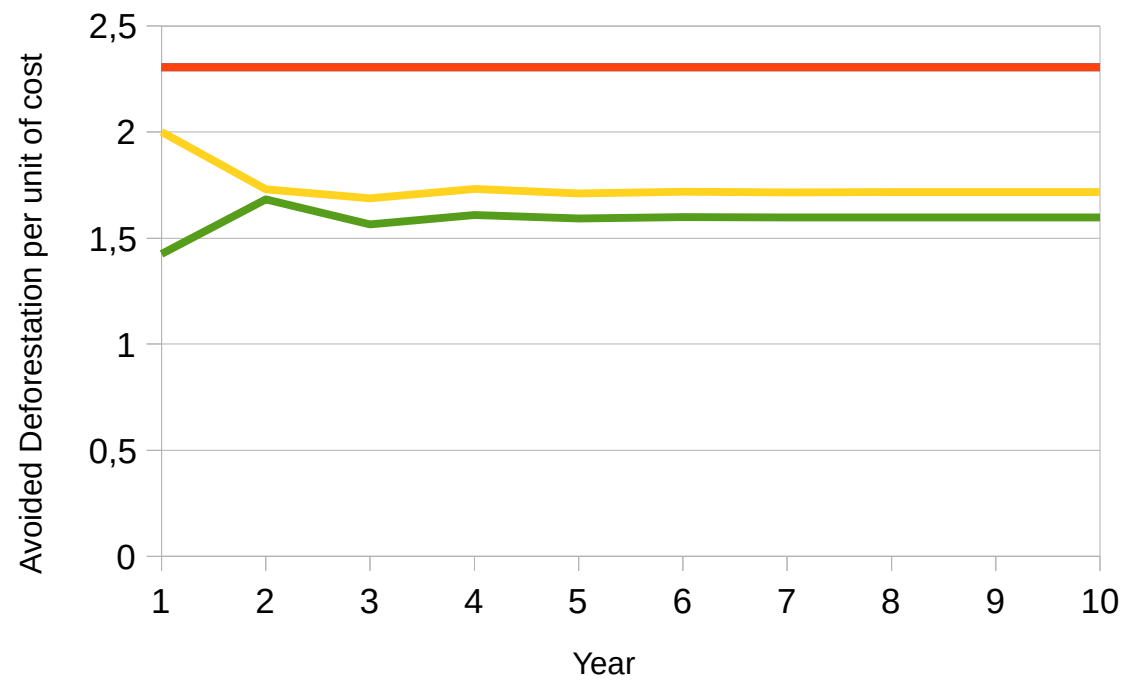

- PES hotspots _ PES full map $C A$ $A B$ 


\section{Dispersed/ High Interactions}

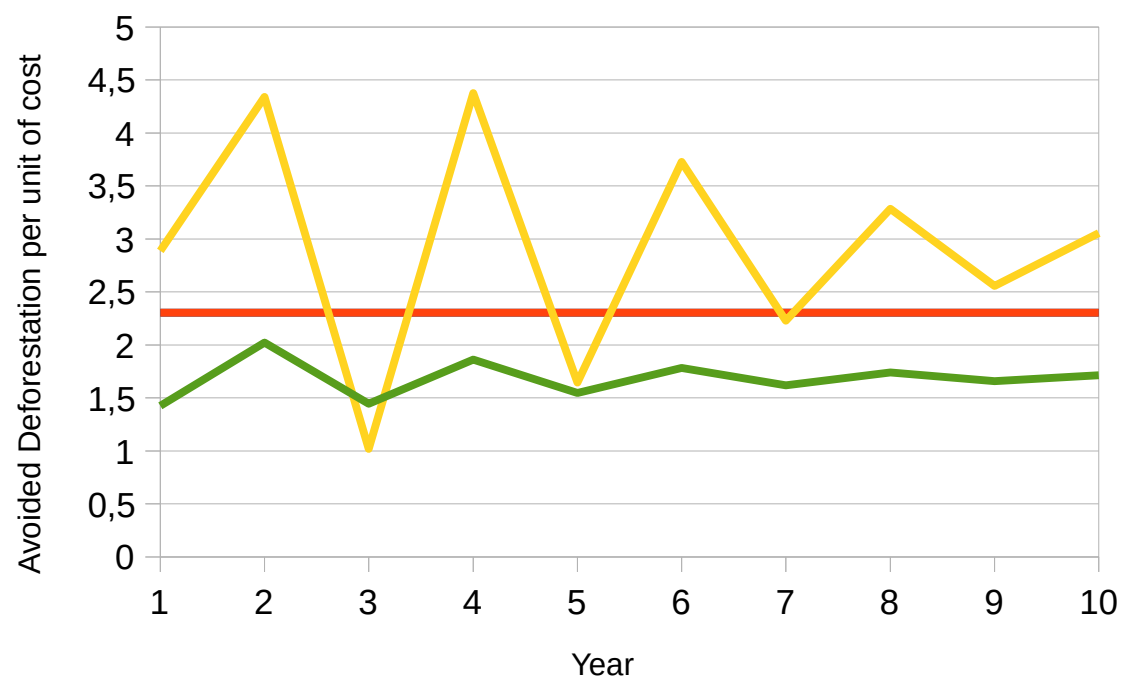

PES hotspots

— PES full map

$C A$

$A B$ 
Clustered/ Low Interactions

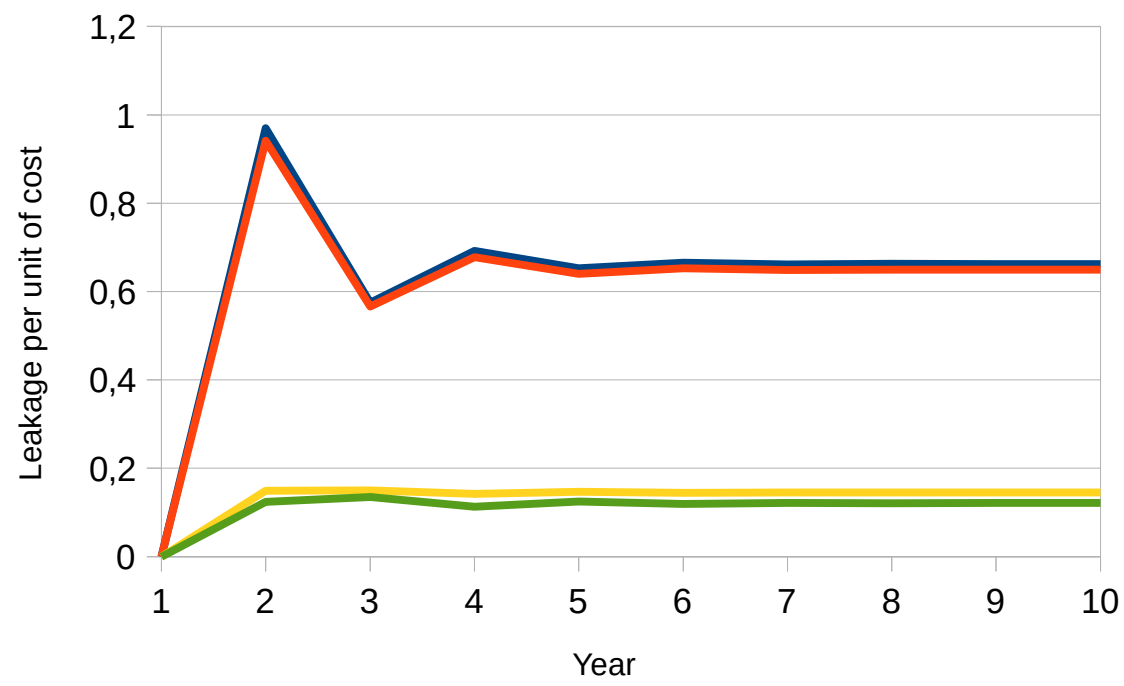

PES hotspots

_ PES full map CA $A B$ 
Clustered/ High Interactions

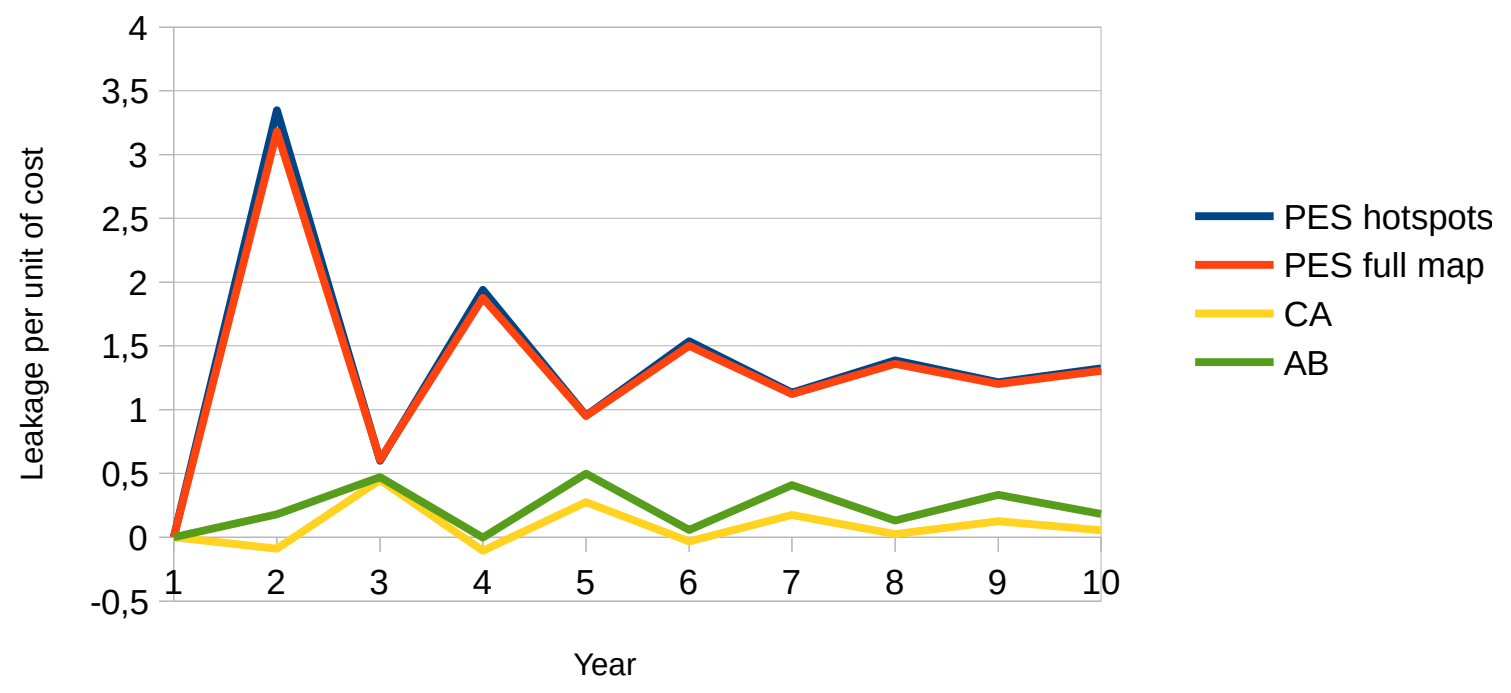




\section{Dispersed/ Low Interactions}

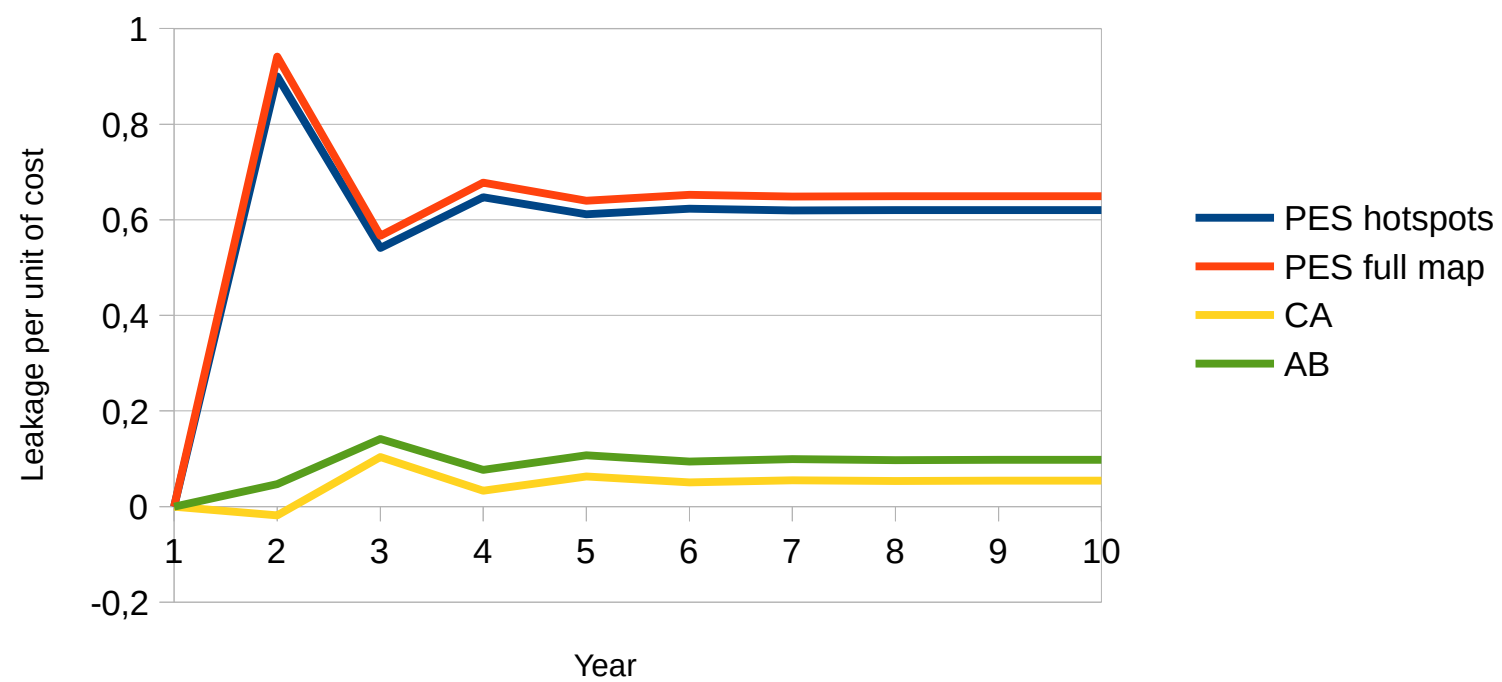


Dispersed/ High Interactions

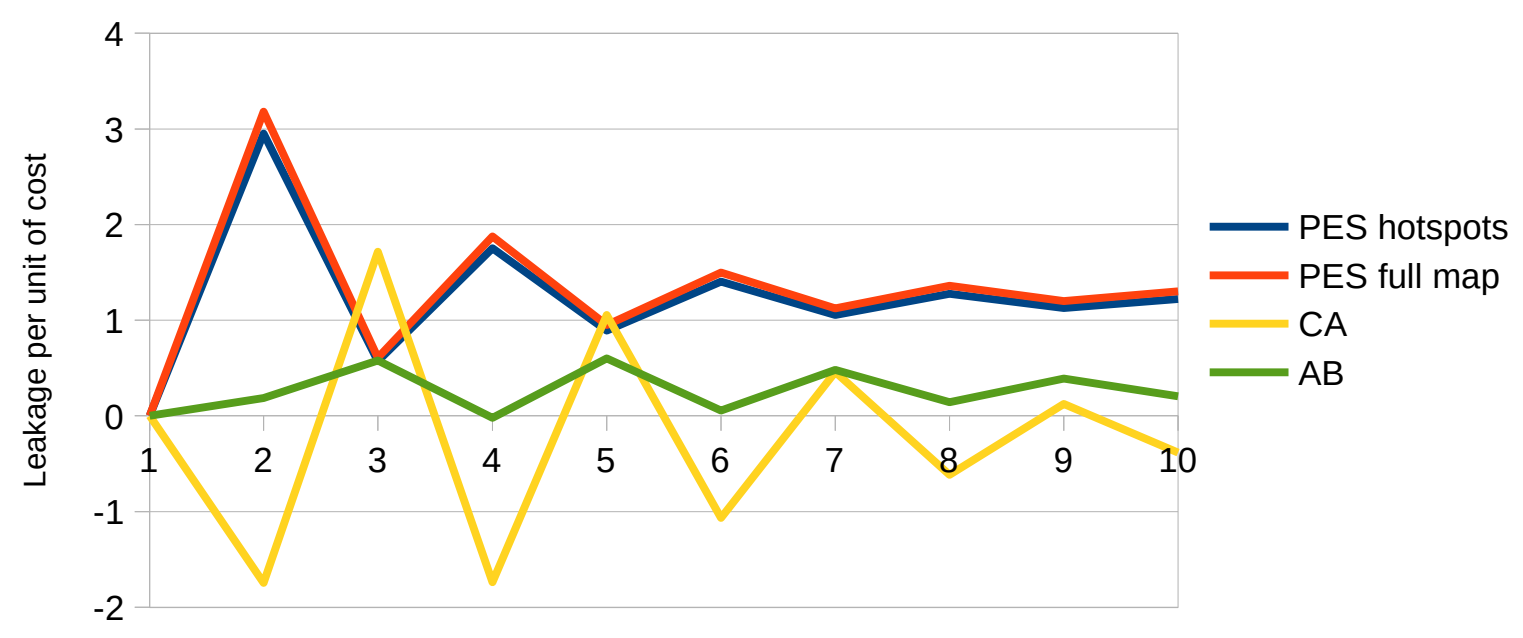




\section{Clustered/ High Interactions}

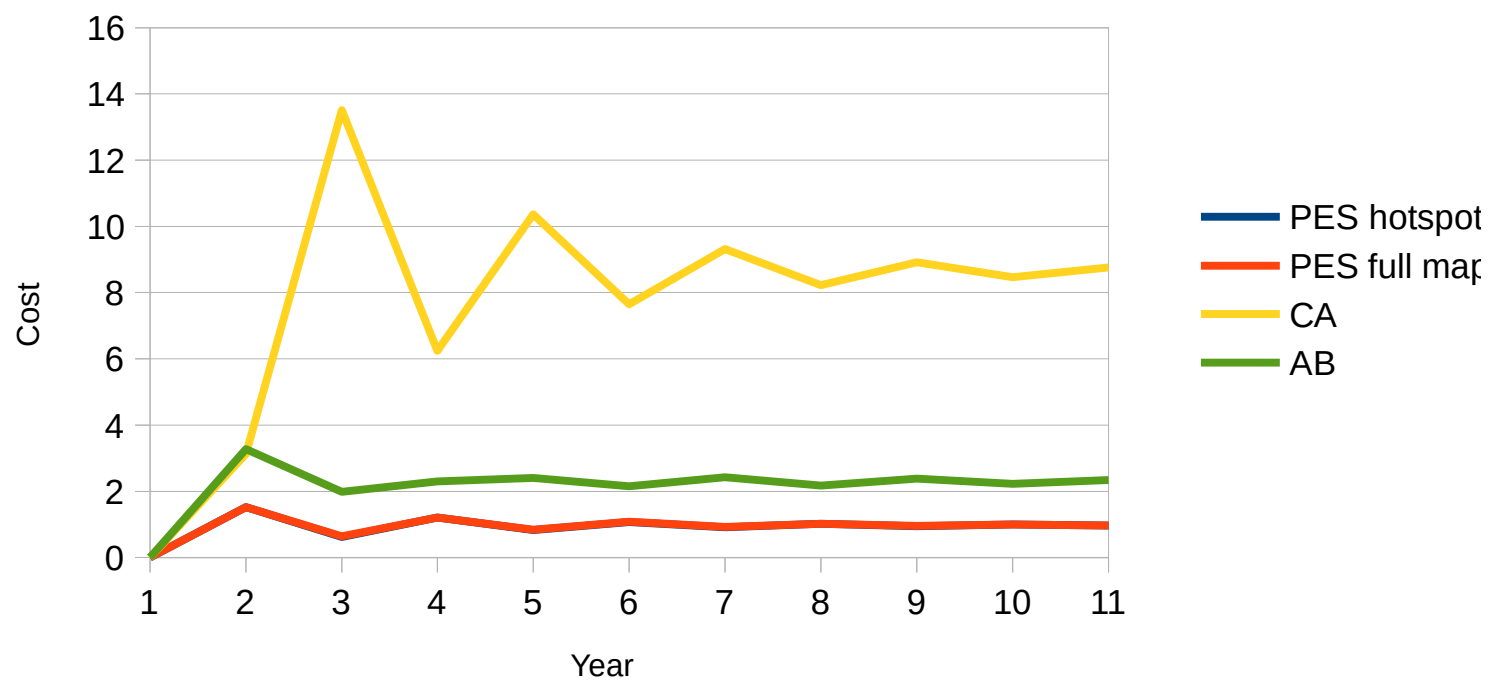




\section{Dispersed/ High Interactions}

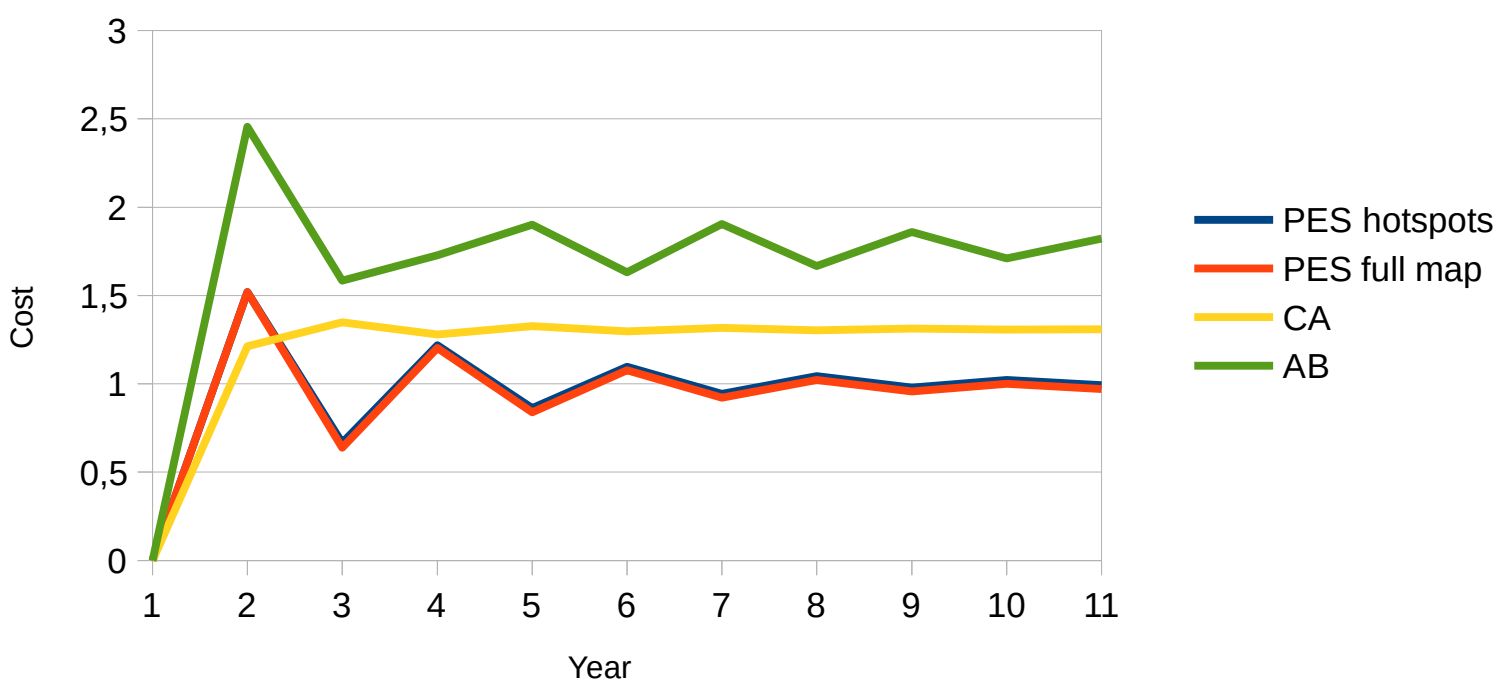


Dispersed/ Low Interactions

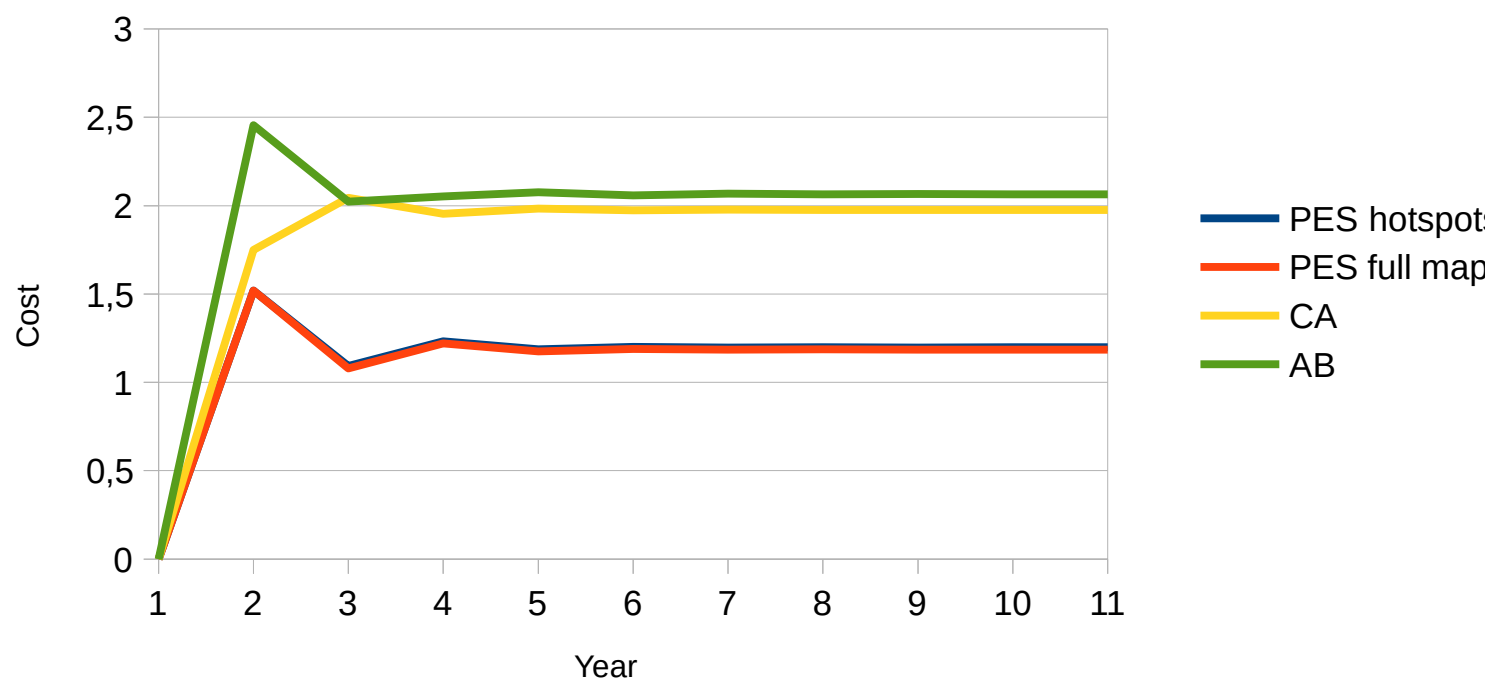


Clustered/ Low Interactions

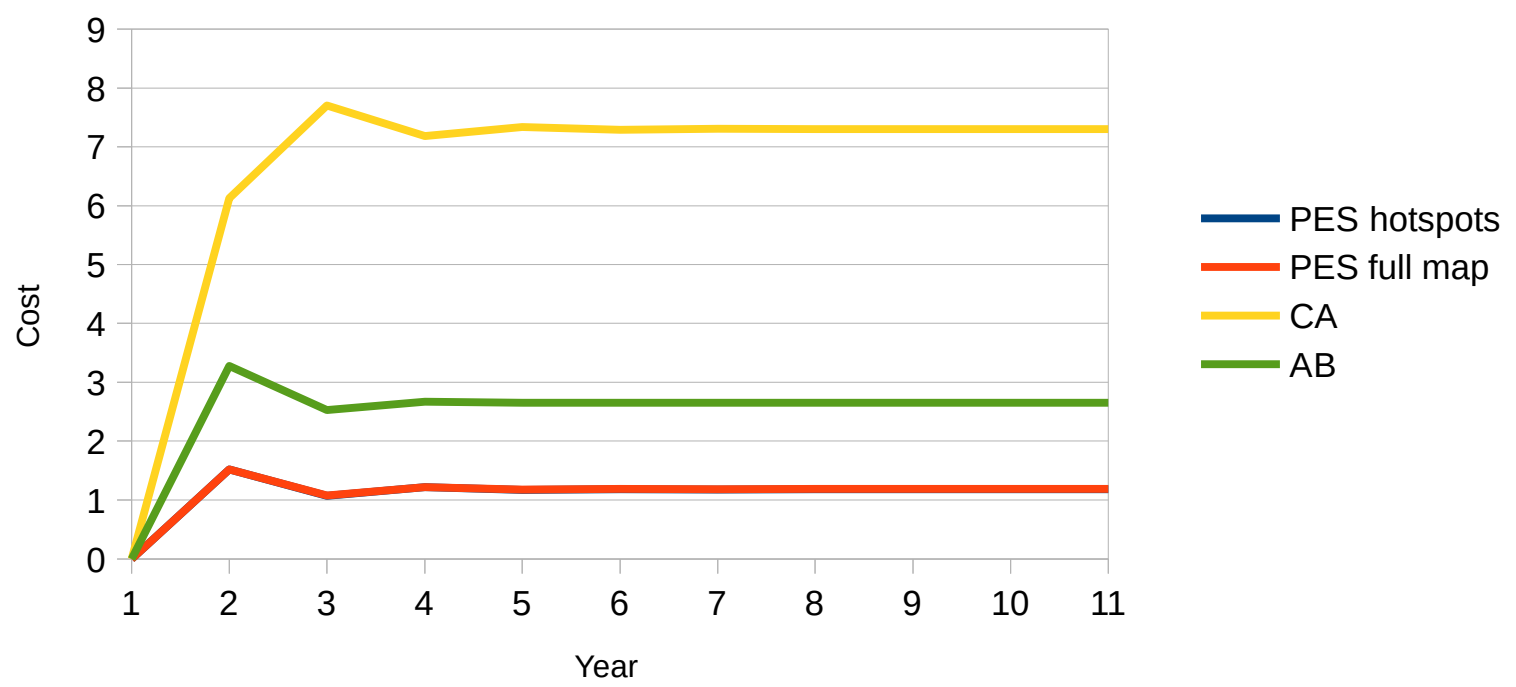


Clustered/ Low Interactions

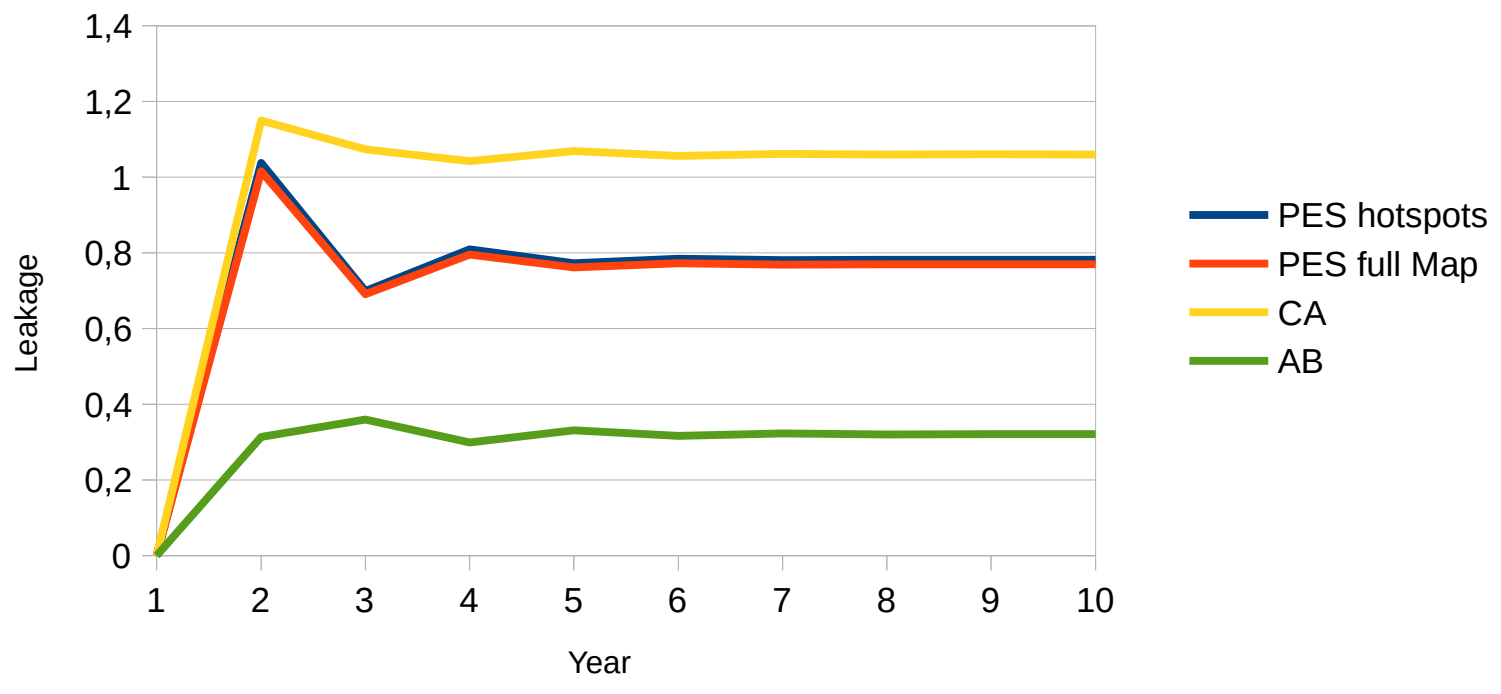




\section{Dispersed/ Low Interactions}

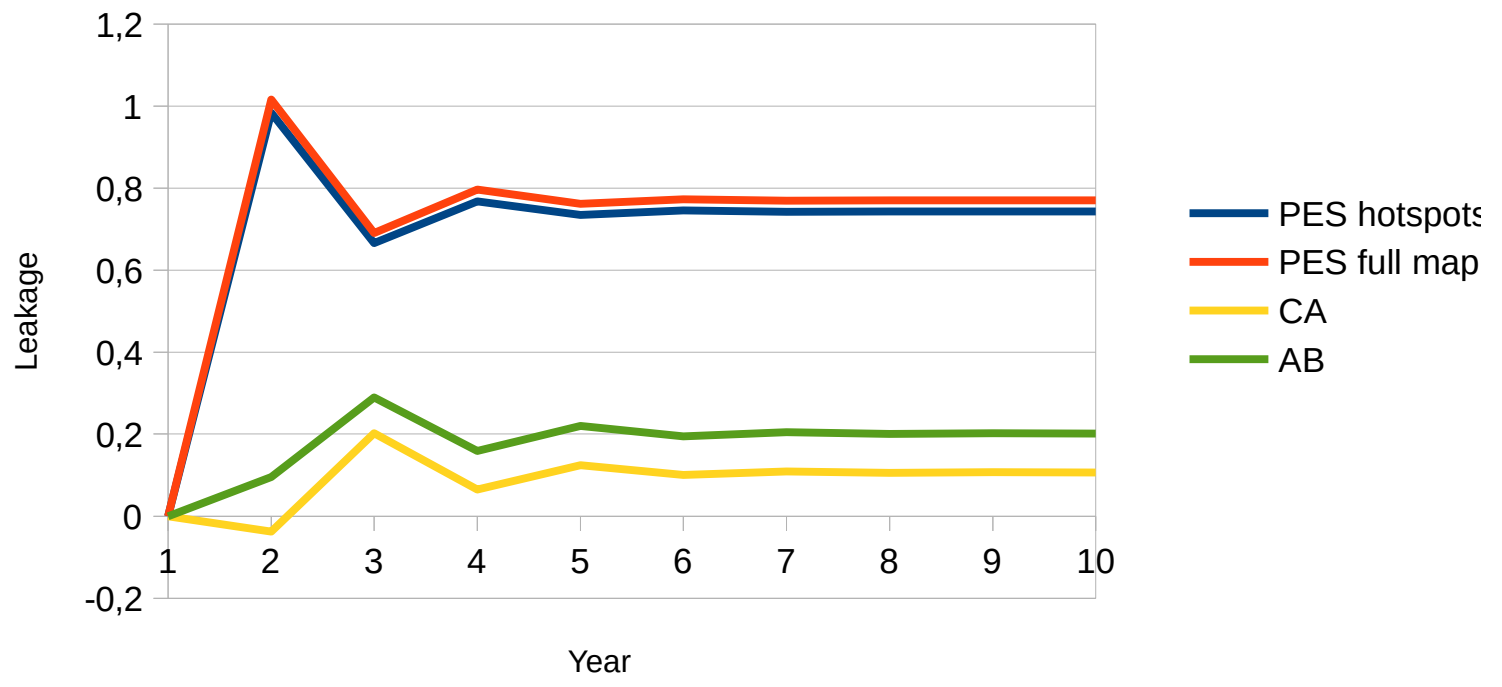


Clustered/ High Interactions

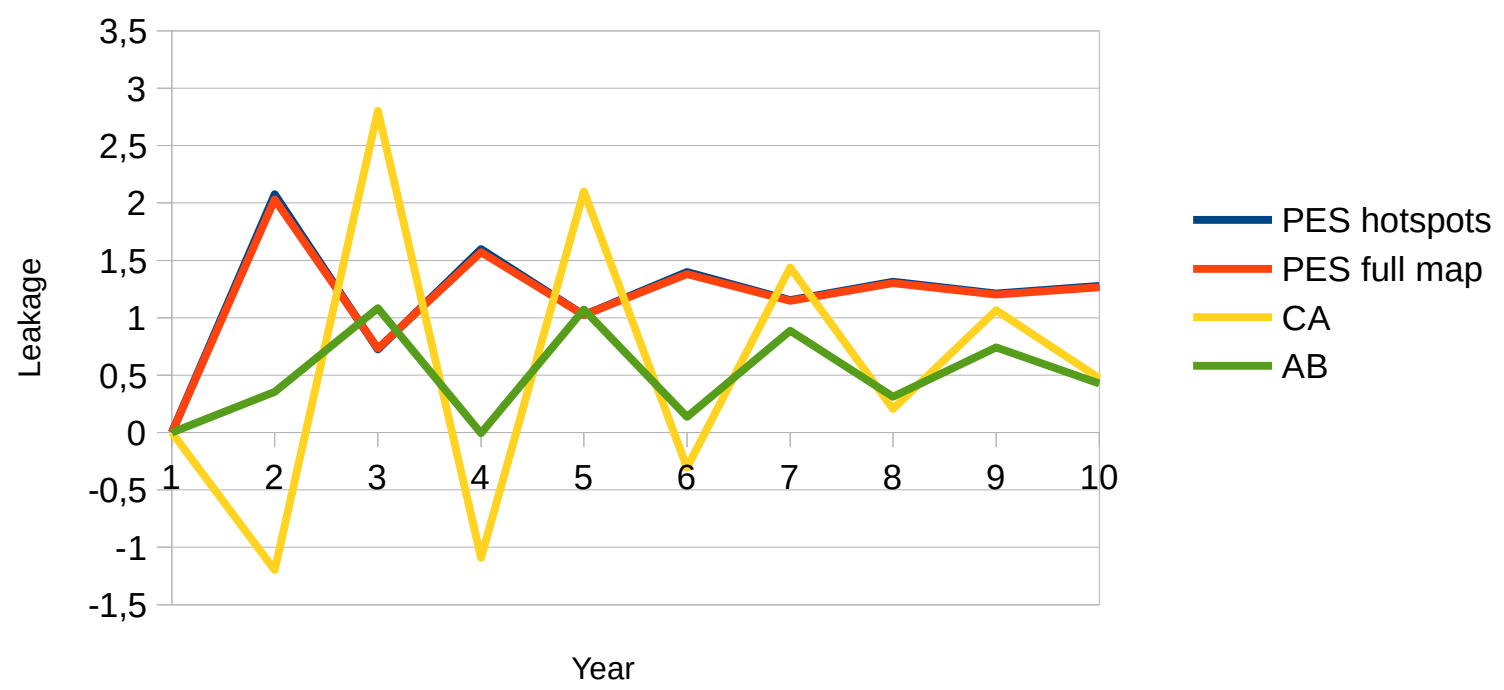




\section{Dispersed/ High Interactions}

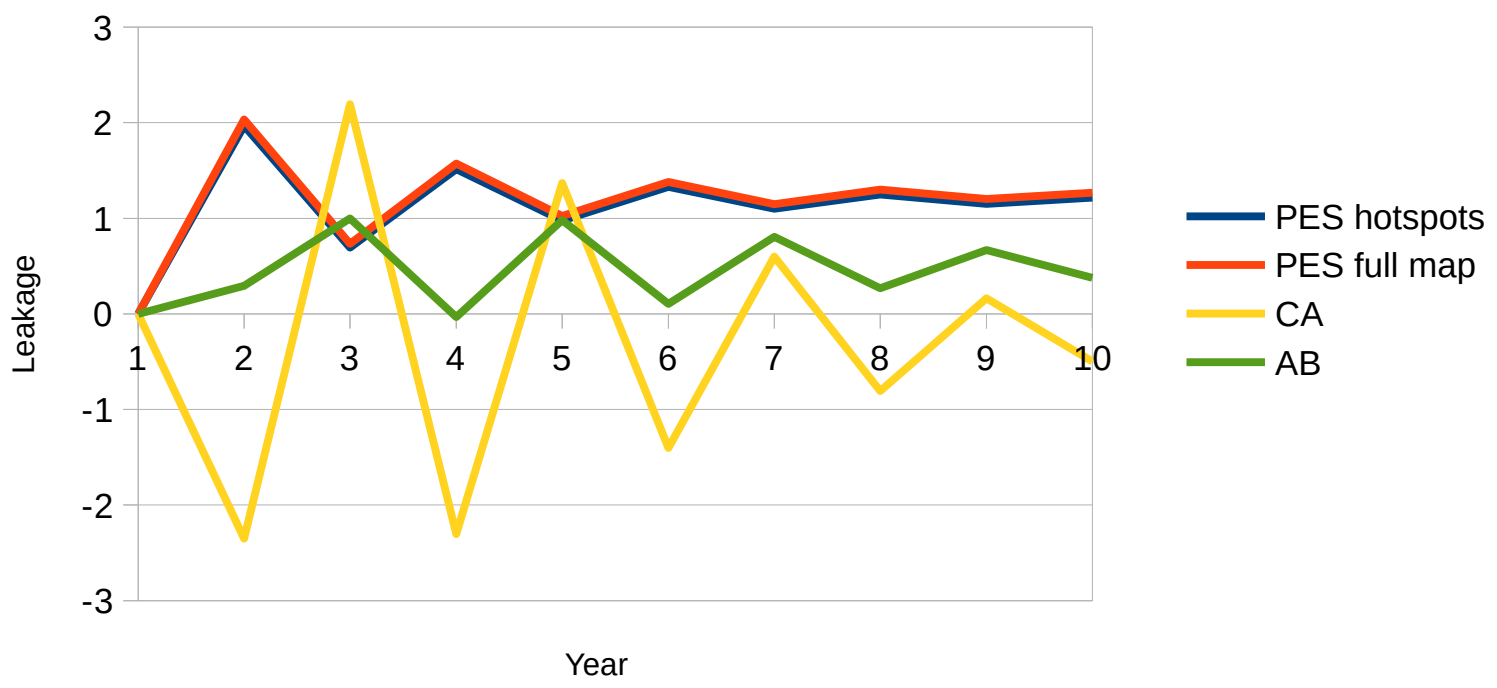


Clustered/ Low Interactions

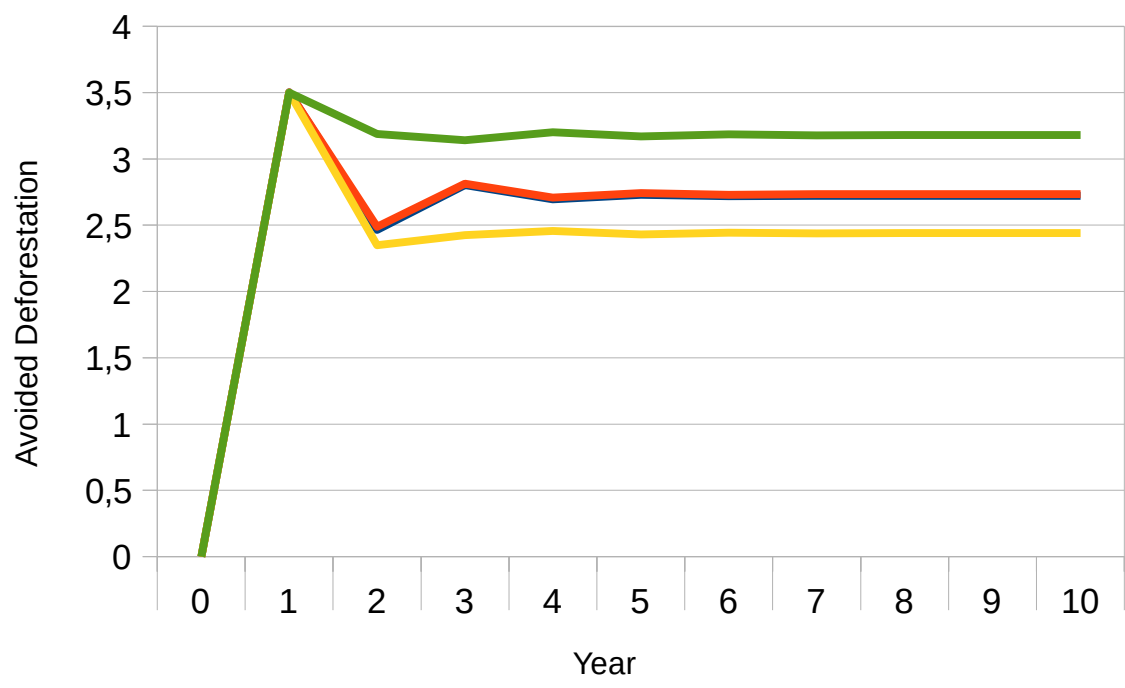




\section{Clustered/ High Interactions}

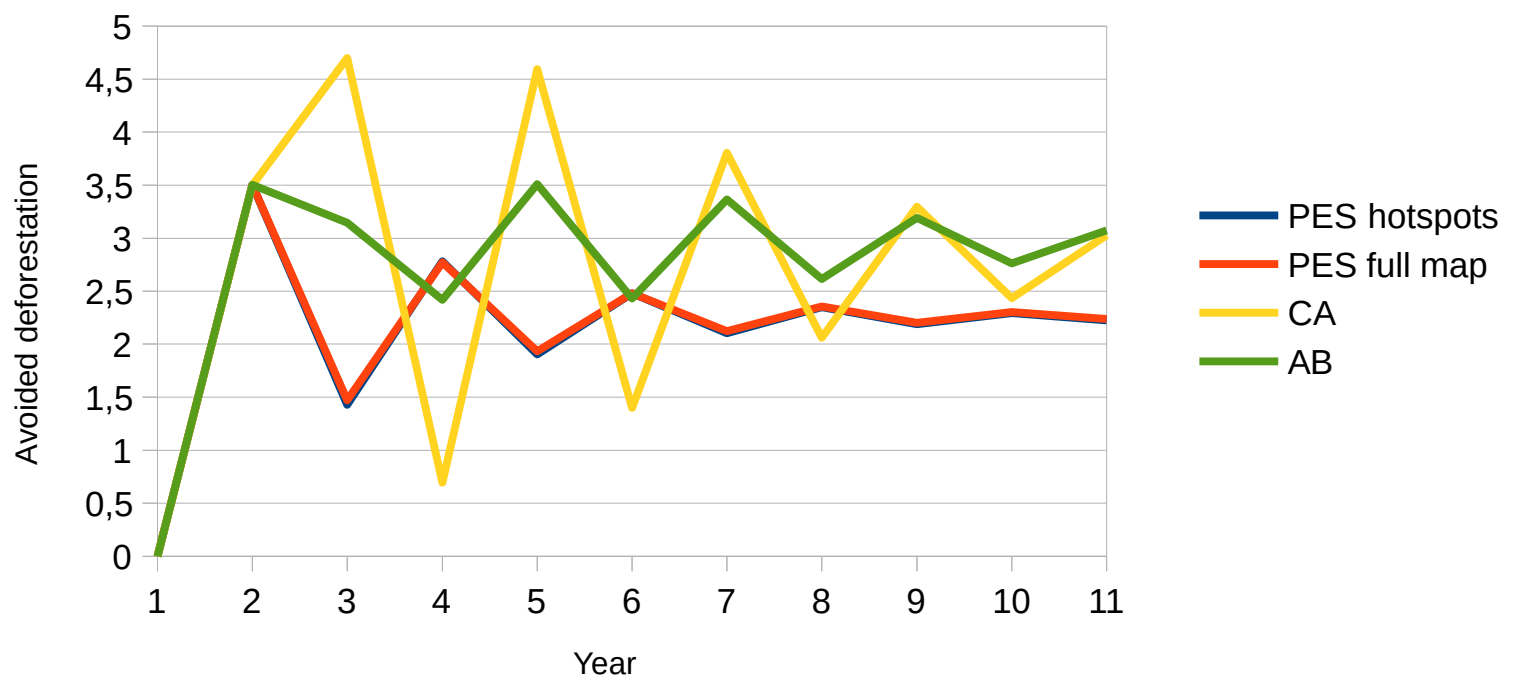




\section{Dispersed/ Low Interactions}

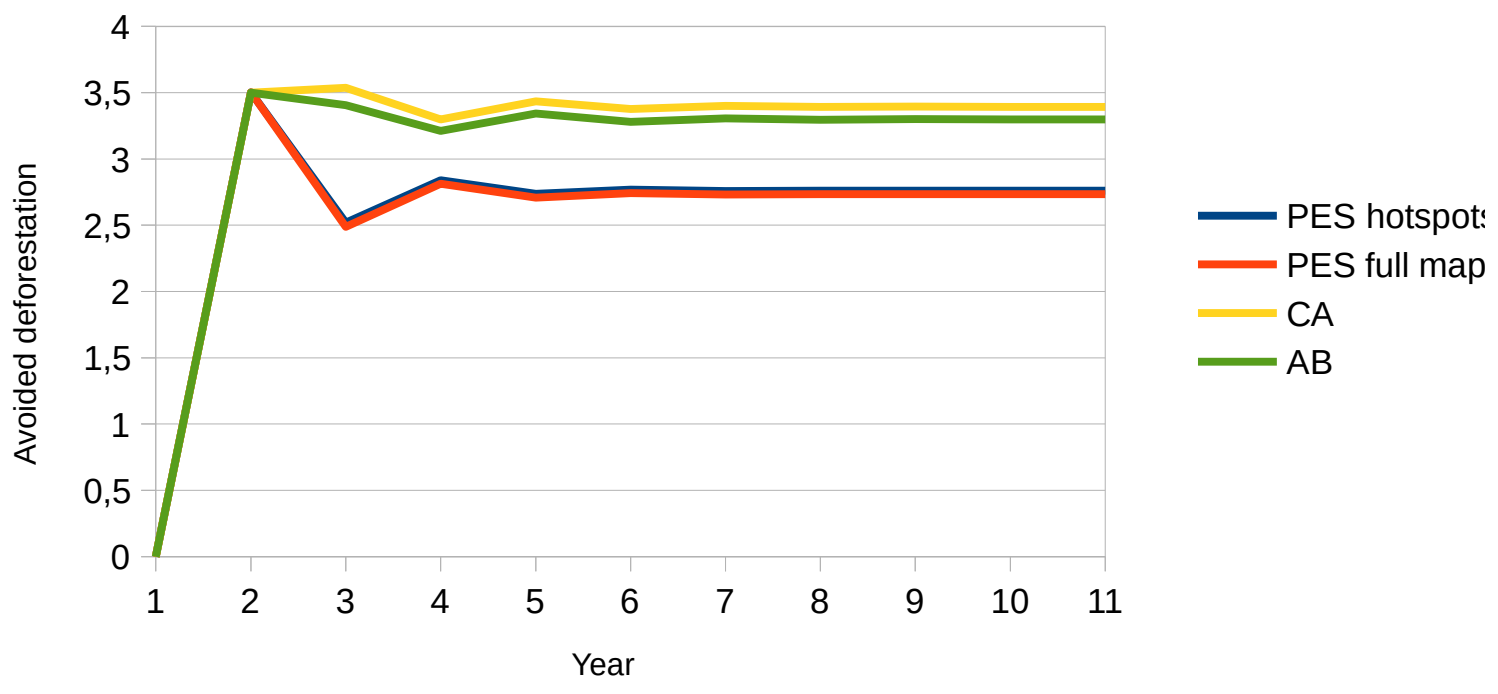




\section{Dispersed/ High Interactions}

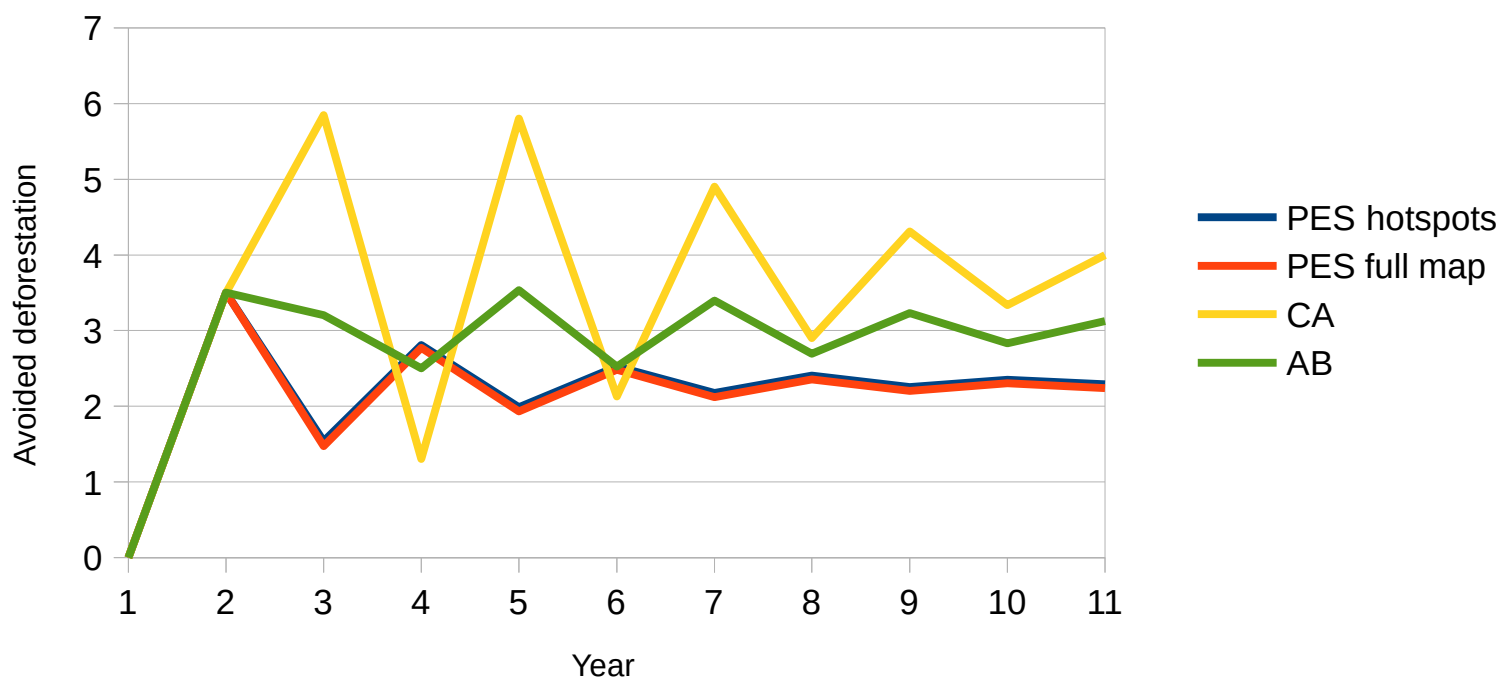


Leakage Intensity

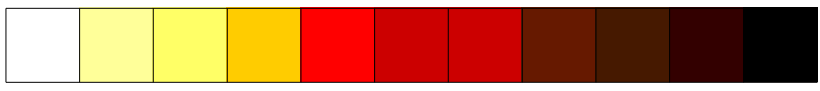

$\mathrm{T}=1$

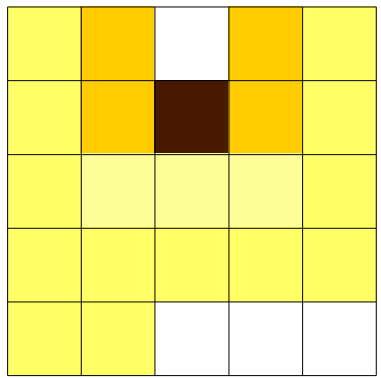

$\mathrm{T}=5$

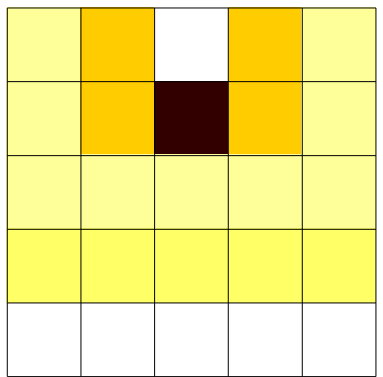

$\mathrm{T}=10$

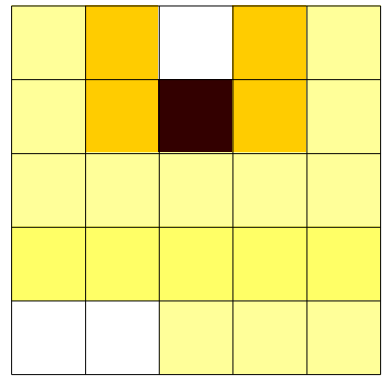




\section{Leakage Intensity}
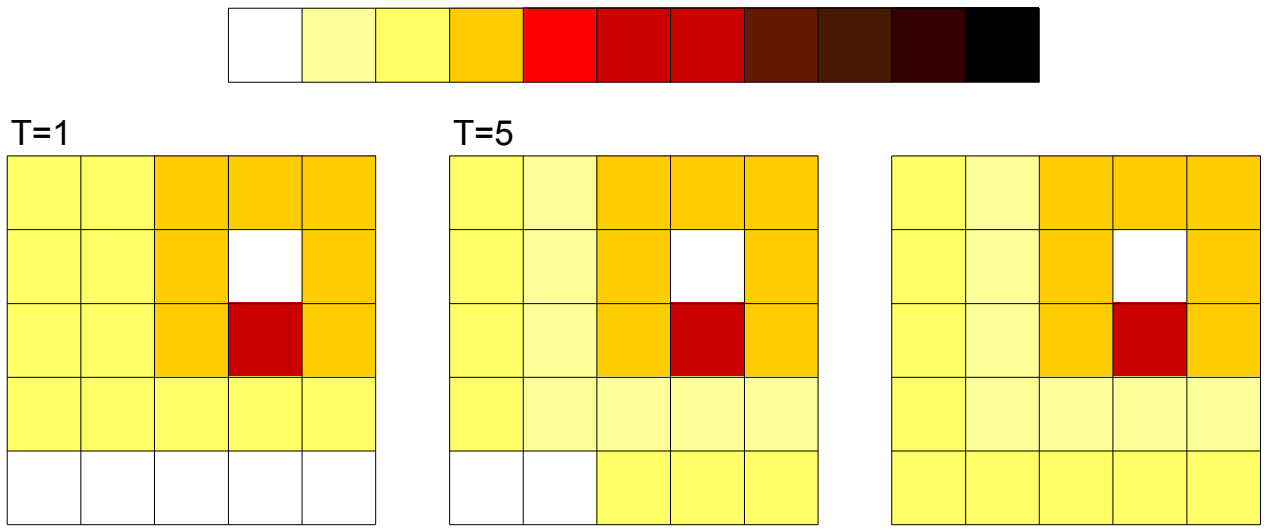


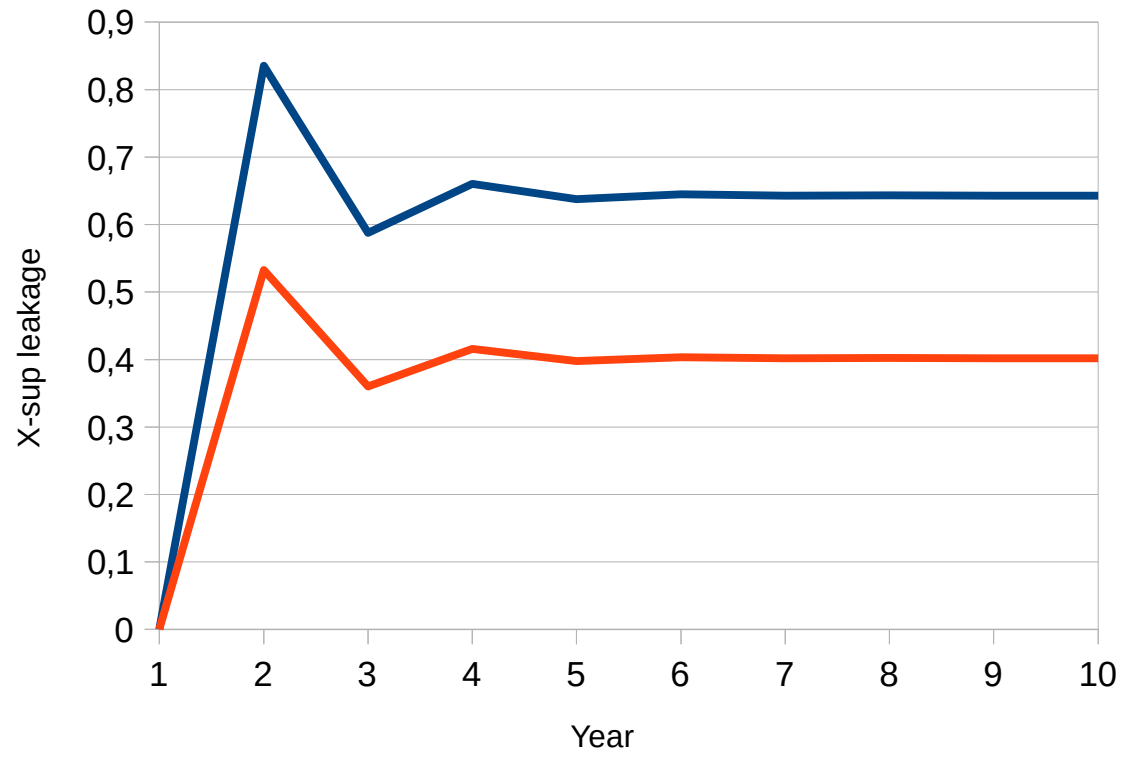




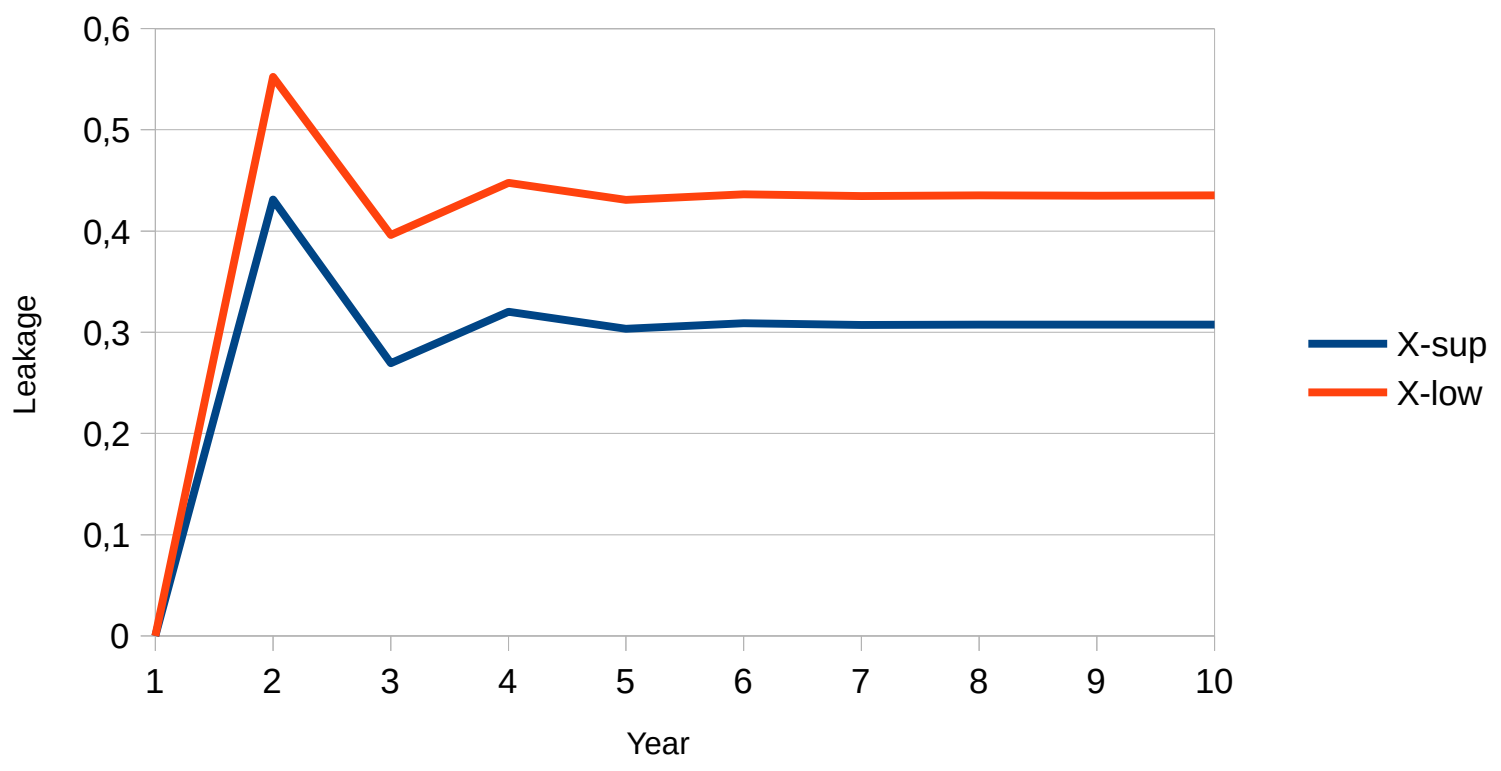




\section{Deforestation Intensity}

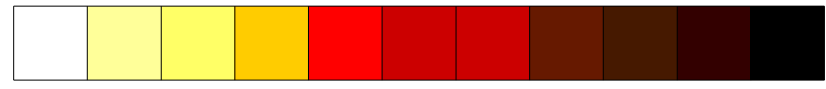

BAU deforestation in the clustered case with low interactions
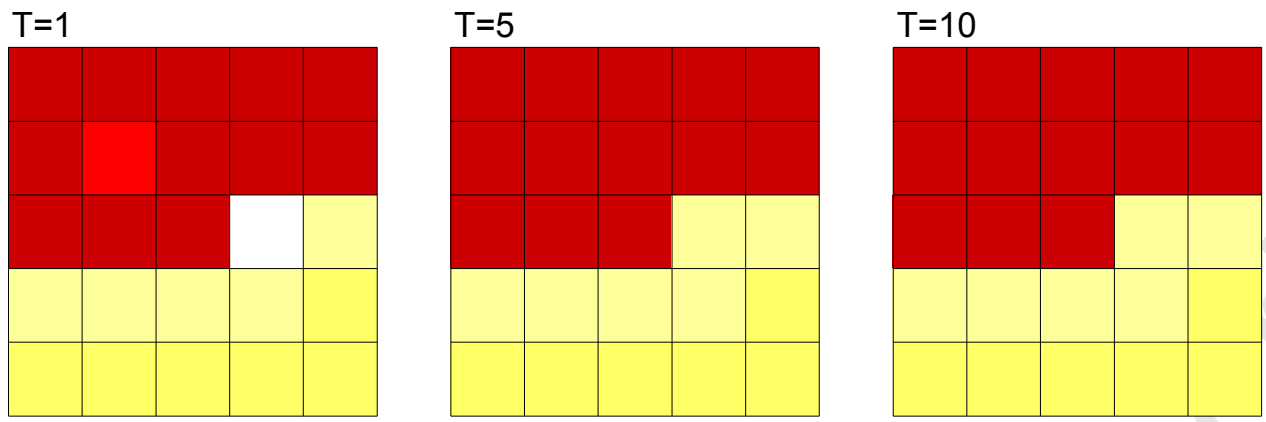

BAU deforestation in the clustered case with high interactions
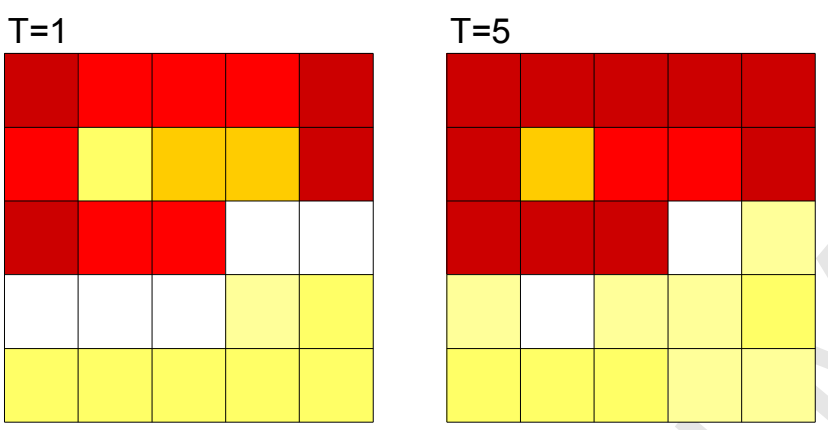

$$
\mathrm{T}=10
$$

BAU deforestation in the dispersed case with low interactions
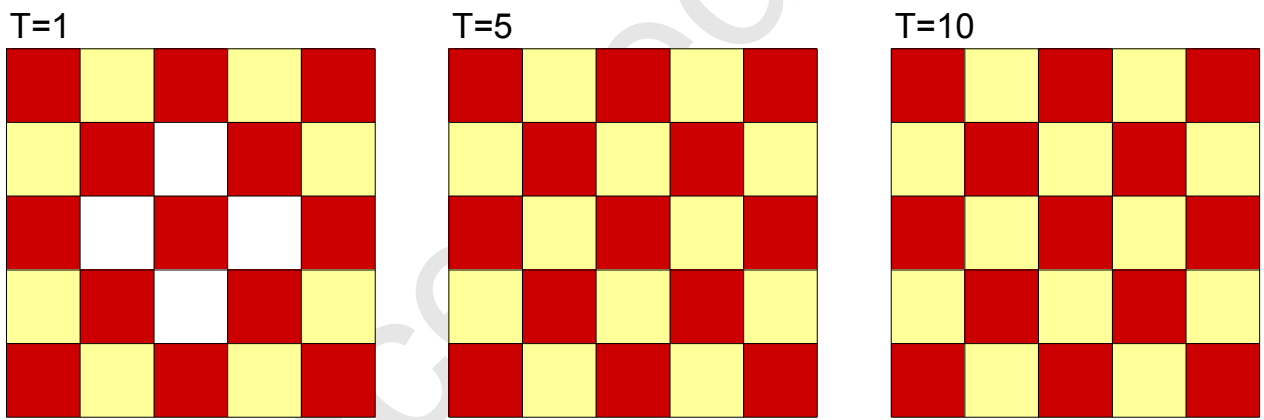

BAU deforestation in the dispersed case with high interactions
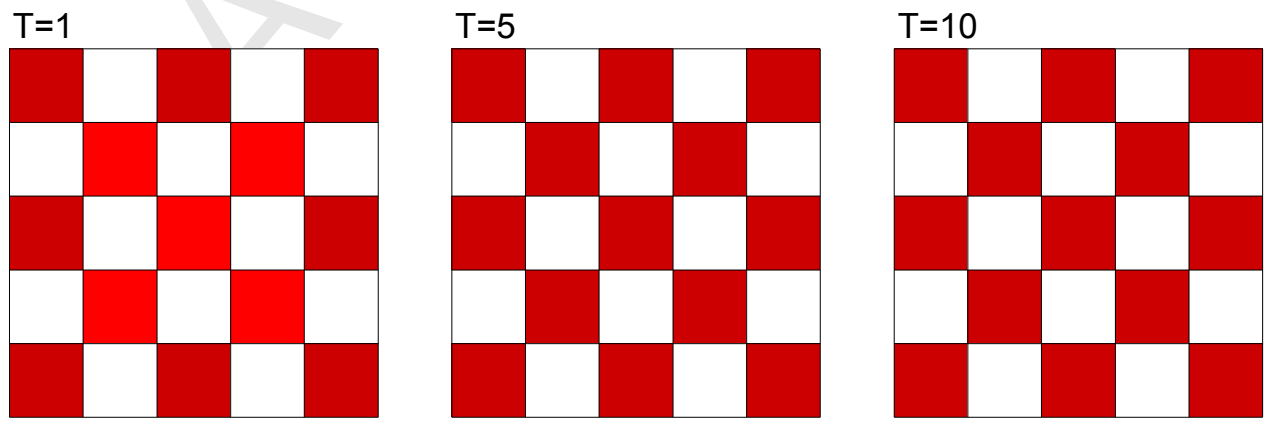


\section{No Policy \\ Spatial Spillovers}

Policy Intervention

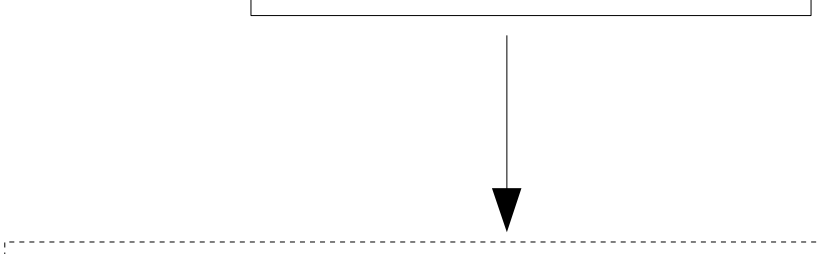

Policy-induced Spatial Spillovers

Leakage

TNT Leakage

Treated $\rightarrow$ Non Treated

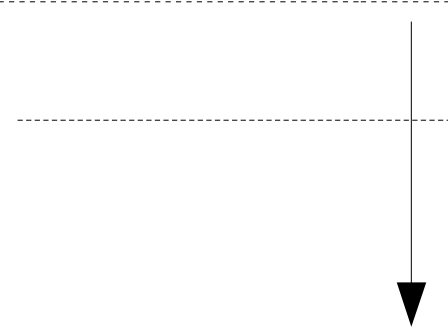

\footnotetext{
NTNT Leakage

Non Treated $\rightarrow$ Non treated
}

\section{Primary Leakage}

\section{TT Leakage \\ Treated $\rightarrow$ Treated}

Secondary Leakage 


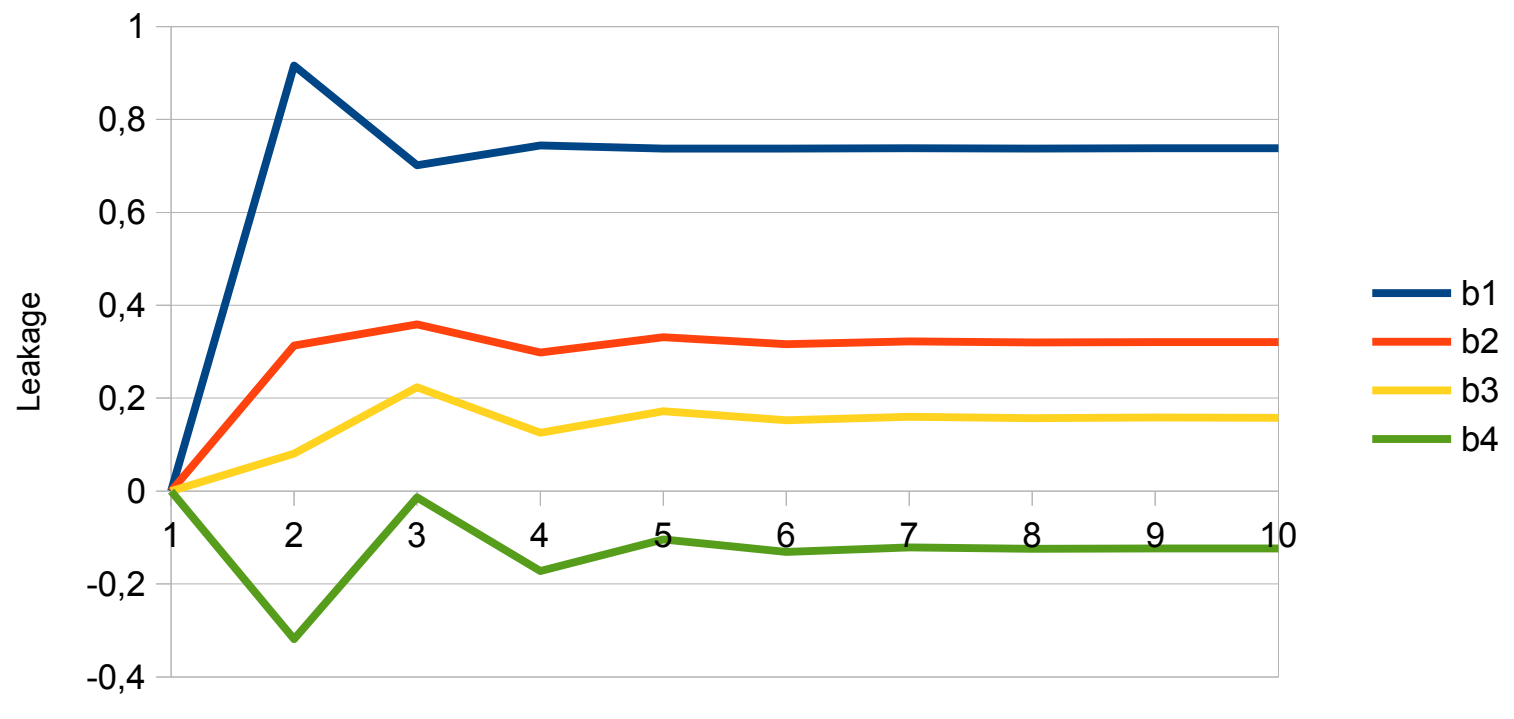

Year 


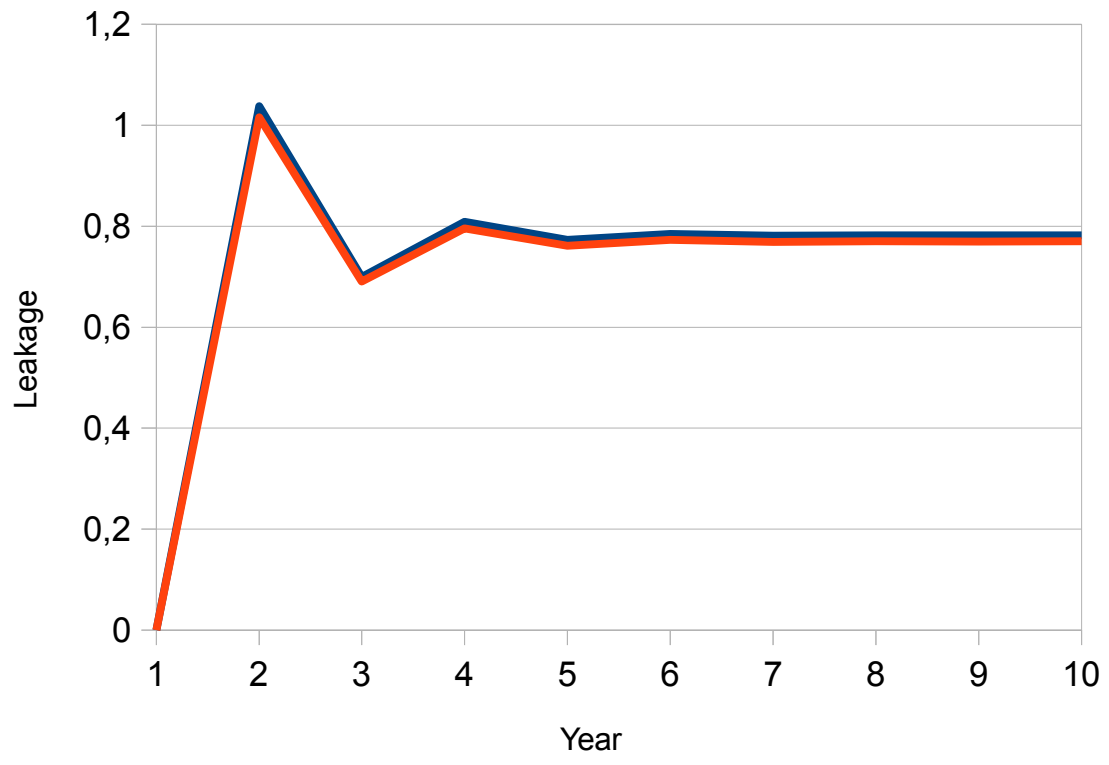

PES hotspots PES Full Map 


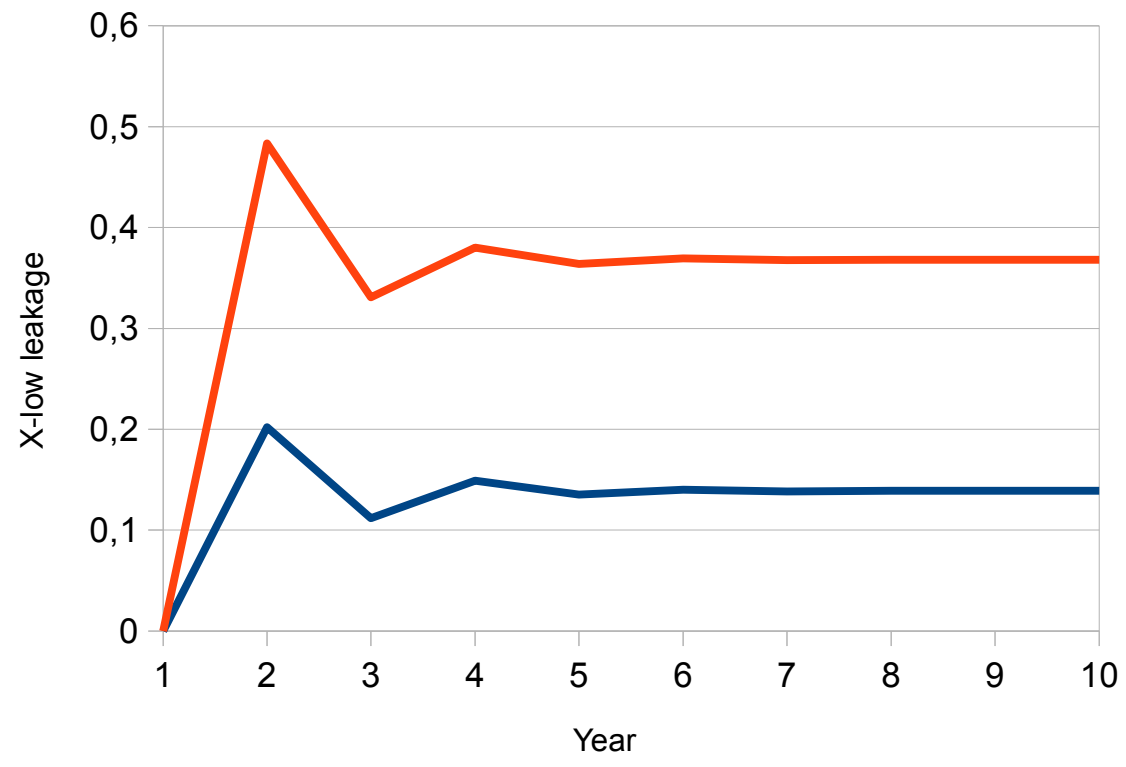




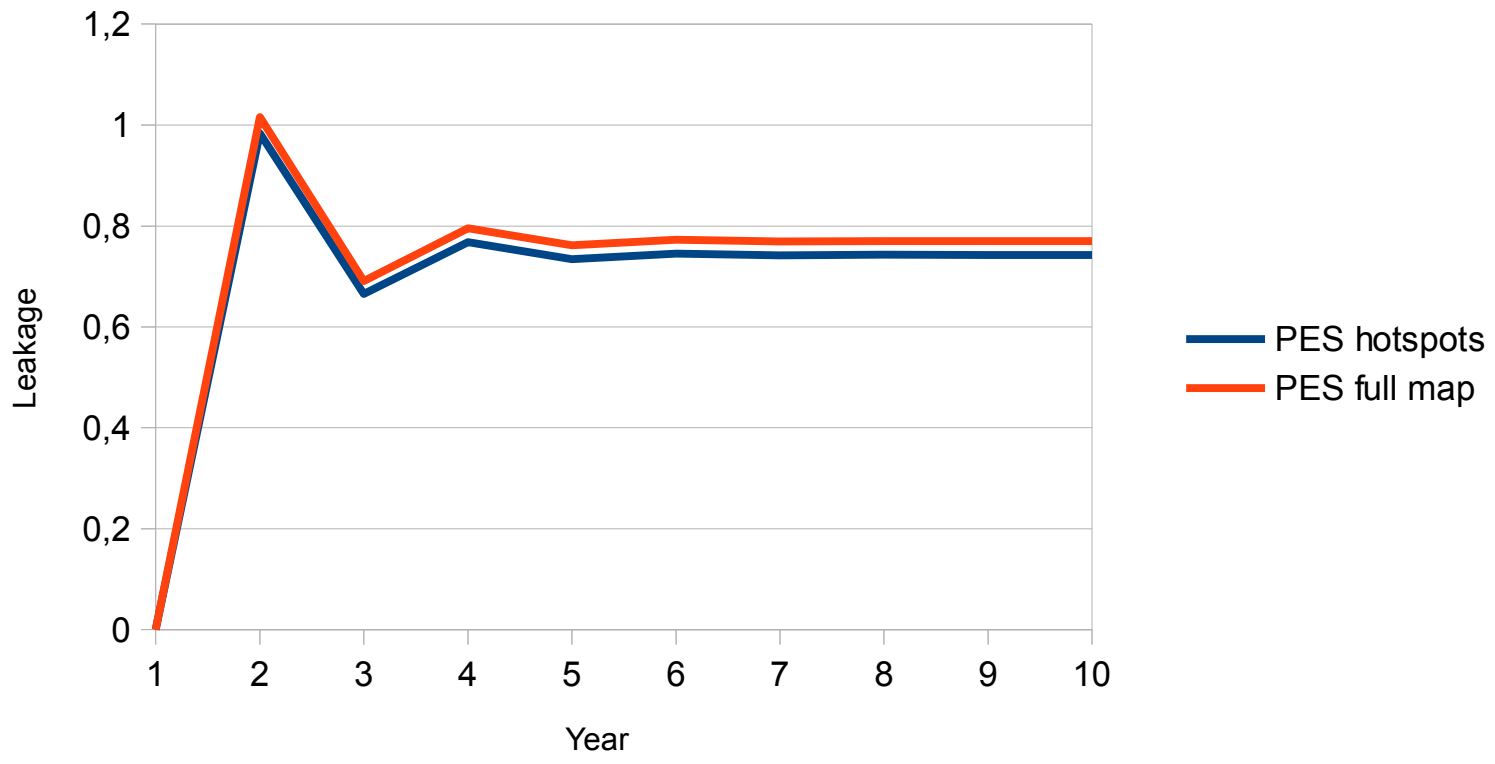




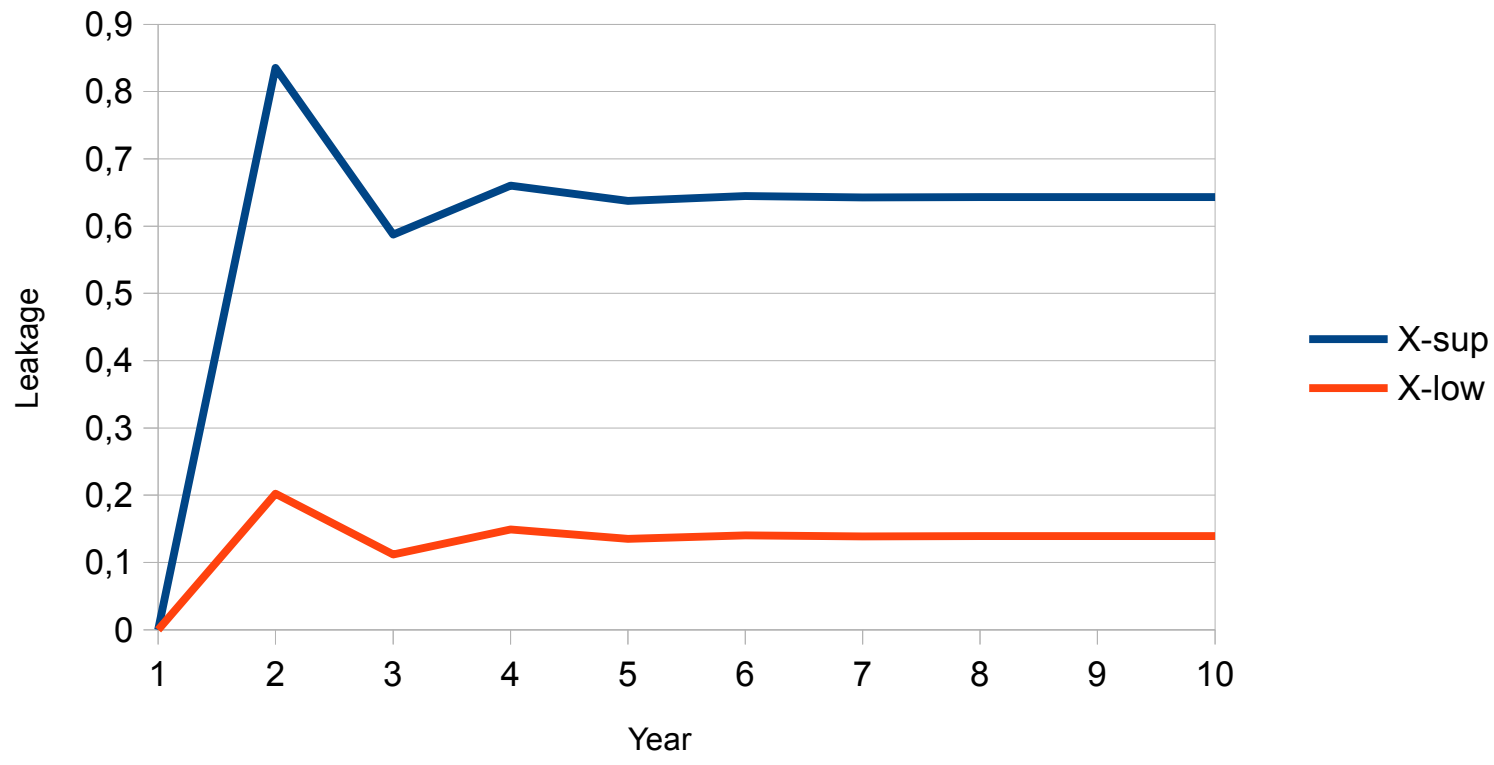

